\title{
The ribosomal protein genes and Minute loci of Drosophila
} melanogaster

\author{
Steven J Marygold*, John Roote ${ }^{\dagger}$, Gunter Reuter, Andrew Lambertsson`, \\ Michael Ashburner ${ }^{\dagger}$, Gillian H Millburn ${ }^{\dagger}$, Paul M Harrison", Zhan Yuđ, \\ Naoya Kenmochi ${ }^{¥}$, Thomas C Kaufman\#, Sally J Leevers* and \\ Kevin R Cook\#
}

\begin{abstract}
Addresses: *Growth Regulation Laboratory, Cancer Research UK London Research Institute, Lincoln's Inn Fields, London WC2A 3 PX, UK. ${ }^{\dagger}$ Department of Genetics, University of Cambridge, Downing Street, Cambridge CB2 3EH, UK. 'Institute of Genetics, Biologicum, Martin Luther University Halle-Wittenberg, Weinbergweg, Halle D-o6108, Germany. §Institute of Molecular Biosciences, University of Oslo, Blindern, Olso N-0316, Norway. "Department of Biology, McGill University, Dr Penfield Ave, Montreal, Quebec H3A 1B1, Canada. ${ }^{¥}$ Frontier Science Research Center, University of Miyazaki, 5200 Kihara, Kiyotake, Miyazaki 889-1692, Japan. \#Department of Biology, Indiana University, E. Third Street, Bloomington, IN 47405-7005, USA.
\end{abstract}

Correspondence: Steven J Marygold. Email: s.marygold@gen.cam.ac.uk. Kevin R Cook. Email: kcook@bio.indiana.edu

Published: 10 October 2007

Genome Biology 2007, 8:R216 (doi:10.1 I86/gb-2007-8-10-r216)

The electronic version of this article is the complete one and can be found online at http://genomebiology.com/2007/8/I0/R216
Received: 17 June 2007

Revised: 10 October 2007

Accepted: 10 October 2007

(c) 2007 Marygold et al.; licensee BioMed Central Ltd.

This is an open access article distributed under the terms of the Creative Commons Attribution License (http://creativecommons.org/licenses/by/2.0), which permits unrestricted use, distribution, and reproduction in any medium, provided the original work is properly cited.

\begin{abstract}
Background: Mutations in genes encoding ribosomal proteins (RPs) have been shown to cause an array of cellular and developmental defects in a variety of organisms. In Drosophila melanogaster, disruption of RP genes can result in the 'Minute' syndrome of dominant, haploinsufficient phenotypes, which include prolonged development, short and thin bristles, and poor fertility and viability. While more than 50 Minute loci have been defined genetically, only 15 have so far been characterized molecularly and shown to correspond to RP genes.

Results: We combined bioinformatic and genetic approaches to conduct a systematic analysis of the relationship between RP genes and Minute loci. First, we identified 88 genes encoding 79 different cytoplasmic RPs (CRPs) and 75 genes encoding distinct mitochondrial RPs (MRPs). Interestingly, nine CRP genes are present as duplicates and, while all appear to be functional, one member of each gene pair has relatively limited expression. Next, we defined 65 discrete Minute loci by genetic criteria. Of these, 64 correspond to, or very likely correspond to, CRP genes; the single non-CRP-encoding Minute gene encodes a translation initiation factor subunit. Significantly, MRP genes and more than 20 CRP genes do not correspond to Minute loci.

Conclusion: This work answers a longstanding question about the molecular nature of Minute loci and suggests that Minute phenotypes arise from suboptimal protein synthesis resulting from reduced levels of cytoribosomes. Furthermore, by identifying the majority of haplolethal and haplosterile loci at the molecular level, our data will directly benefit efforts to attain complete deletion coverage of the $D$. melanogaster genome.
\end{abstract}




\section{Background}

Ribosomes are sophisticated macromolecular machines that catalyze cellular protein synthesis in all cells of all organisms. They have an ancient evolutionary origin and are essential for cell growth, proliferation and viability. Though larger and more complex in higher organisms, both the structure and function of ribosomes have been conserved throughout evolution. Genetic approaches in Drosophila melanogaster have shown that disrupting ribosome function can result in an array of fascinating dominant phenotypes $[1,2]$. Despite this, there has so far been no comprehensive inventory of genes encoding ribosome components in this organism, nor any systematic effort to determine their mutant phenotypes.

All ribosomes comprise a set of ribosomal proteins (RPs) surrounding a catalytic core of ribosomal RNA (rRNA). Bacteria possess a single type of ribosome composed of three rRNA molecules and typically 54 RPs. All eukaryotic cells, in contrast, contain at least two distinct types of ribosomes: cytoplasmic ribosomes (cytoribosomes) and mitochondrial ribosomes (mitoribosomes). Cytoribosomes are found on the endoplasmic reticulum and in the aqueous cytoplasm. They translate all mRNAs produced from nuclear genes and perform the vast majority of cellular protein synthesis. Each cytoribosome contains four different rRNAs and 78-80 cytoplasmic RPs (CRPs). Mitoribosomes consist of only two rRNA molecules and up to 80 mitochondrial RPs (MRPs). They are located in the mitochondrial matrix and synthesize proteins involved in oxidative phosphorylation encoded by those few genes retained in the mitochondrial genome. A third unique type of eukaryotic ribosome is found within the plastids (for example, chloroplasts) of plant and various algal cells. In all cases, distinct small and large ribosomal subunits exist that join together during the translation initiation process to form mature ribosomes capable of protein synthesis. (See references [3-6] for general reviews of ribosomal structure and function.)

The protein components of ribosomes are interesting from several points of view. First, and most obviously, RPs play critical roles in ribosome assembly and function [7]. Second, several RPs perform important extra-ribosomal functions, including roles in DNA repair, transcriptional regulation and apoptosis $[6,8]$. Third, misexpression of human CRP and MRP genes has been implicated in a wide spectrum of human syndromes and diseases, including Diamond-Blackfan anaemia [9], Turner syndrome [10], hearing loss [11] and cancer [12]. Fourth, mutations in the CRP genes of D. melanogaster are important tools for the study of growth, development and cell competition [2]. Finally, many RPs are conserved from bacteria to humans, so their peptide and nucleotide sequences are useful for studying phylogenetic relationships [13].

The first eukaryotic CRPs characterized in detail were isolated from the rat cytoribosome [3]. Individual proteins were separated by two-dimensional gel electrophoresis and named from their origin in the small (S) or large (L) subunit and their relative electrophoretic migration positions, for example, RPS9 or RPL28. Subsequent studies revealed that some protein spots contained non-ribosomal proteins or chemically modified versions of another CRP, and that some spots contained two co-migrating CRPs [3,5]. Consequently, the nomenclature system used today contains numerical gaps as well as 'A' suffixes for those additional CRPs not resolved by the original electrophoresis (for example, RPL36A). Seventynine distinct mammalian CRPs are now acknowledged and their amino acid sequences and biochemical properties have been described $[5,14]$. With the exception of RPLP1 and RPLP2, each of which forms homodimers in the cytoribosomal large subunit [15], all CRPs are present as single molecules in each cytoribosome [3].

Seventy-eight different mammalian MRPs have been described [6] and their individual amino acid sequences and biochemical properties have been determined [16,17]. Although the nomenclature of MRPs was originally based on electrophoretic properties, the current system reflects homology between mammalian MRPs and their bacterial orthologs [18]. Thus, MRPS1 through MRPS21 are orthologous to Escherichia coli RPs S1-S21, while higher numbers have been assigned to the MRPs not found in bacteria. Gaps also exist in MRP numbering because a gap occurs in the bacterial enumeration or because there is no mammalian ortholog.

The RPs of D. melanogaster were first studied in the 1970 s and early 1980 s. Up to 78 individual CRPs were observed on two-dimensional gels [19-31] and about 30 were purified and analyzed biochemically $[32,33]$. A more recent characterization used mass spectrometry to identify $52 \mathrm{D}$. melanogaster CRPs [34], all of which are orthologous to known mammalian CRPs. The protein composition of Drosophila mitoribosomes has not been characterized biochemically to date.

CRPs and MRPs are encoded by the nuclear genome. Knowledge of the primary sequences of rat CRPs and bovine MRPs has led to the identification and mapping of the RP-encoding genes in many eukaryotic species [14]. Indeed, systematic analyses of whole RP gene sets have been described for several organisms, including Saccharomyces cerevisiae [35], Arabidopsis thaliana [36] and humans [37-40]. However, the complete set of $D$. melanogaster CRP and MRP genes has not been previously documented or characterized.

Several $D$. melanogaster RP genes were initially identified by virtue of their dominant 'Minute' mutant phenotypes [2], which include prolonged development, low fertility and viability, altered body size and abnormally short, thin bristles on the adult body. All of these phenotypes may be explained by a cell-autonomous defect in protein biosynthesis: the production of each bristle, for example, requires a very high rate of 
protein synthesis in a single cell during a short developmental period. Merriam and colleagues reported the first unequivocal molecular link between a Minute locus and a CRP gene in 1985 [41]. Since then, 14 additional Minute loci have been definitively linked with distinct CRP genes [2,42-53]. However, there are at least 35 genetically validated Minute loci that have not yet been associated with a specific gene and there may be additional Minute genes to be discovered. Several investigators have hypothesized that all Minute loci encode protein components of ribosomes (reviewed in [2]). Whether this is truly the case and whether both CRP and MRP genes are associated with Minute phenotypes are open and intriguing questions.

Many Minute loci were originally identified from the phenotypes of flies heterozygous for a chromosomal deletion $[54,55]$ and all Minute point mutations studied in depth have been found to be loss-of-function alleles [2]. This indicates that Minute phenotypes can be attributed to genetic haploinsufficiency; that is, a single gene copy is not sufficient for normal development. (Note that $X$-linked mutations that cause Minute phenotypes in heterozygous females are lethal in hemizygous males.) The most popular explanation for the haploinsufficiency of Minute loci is that they correspond to RP genes and that RPs are required in equimolar amounts: halving the copy number of a single RP gene limits the availability of the encoded RP, thereby reducing the number of functional ribosomes that are assembled in the cell and impairing protein synthesis [2]. While this idea is consistent with the available data, there may be other explanations.

The reduced fertility and viability associated with many Minute loci makes the recovery of deletions uncovering them rather difficult - the mutant strains are too weak to maintain as stable heterozygous stocks. In fact, some Minute loci are known only from the phenotypes of transient aneuploids $[54,56]$. This means that several chromosomal regions containing a Minute locus are not uncovered by current deletion collections [57]. This is frustrating for researchers because deletions are basic tools for mutational analysis and are widely used for mapping new mutations and identifying genetic modifiers. Efforts to maximize deletion coverage of the D. melanogaster genome would benefit from a systematic assessment of the relationship between RP genes and Minute loci. It would allow the isolation of deletions that flank haploinsufficient RP genes as closely as possible, or the design of transgenic constructs or chromosomal duplications to rescue the haploinsufficiency of deletions uncovering Minute genes.

Here, we report the systematic identification, naming and characterization of all the CRP and MRP genes of D. melanogaster. We have used this information, together with phenotypic data obtained from examining mutation and deficiency strains, to assess the correspondence between RP genes and Minute loci. We find that 66 of the 88 CRP genes identified are, or are very likely to be, haploinsufficient and associated with a Minute phenotype, whereas MRP genes and the remaining 22 CRP genes are not. Significantly, we show that all but one of the known Minute loci in the genome correspond to CRP genes - the single exception encodes a subunit of an essential translation initiation factor. Together, these results identify the majority of haploinsufficient loci in the D. melanogaster genome that significantly affect viability, fertility and/or external morphology, and also provide a mechanistic framework for understanding the Minute syndrome and the phenotypic effects of aneuploidy.

\section{Results \\ Identification of D. melanogaster ribosomal protein genes}

In order to conduct an exhaustive survey of Drosophila CRP and MRP genes, we first performed a series of BLAST searches using human RP sequences as queries, because both CRPs and MRPs have been well-characterized in humans $[5,6]$. Tables 1 and 2 list the genes we identified together with their cytological locations. Where necessary, D. melanogaster genes were named or renamed according to the standard metazoan RP gene nomenclature proposed by Wool and colleagues $[5,58,59]$ and approved by the HUGO Gene Nomenclature Committee [18], whilst still conforming to FlyBase [6o] conventions - that is, CRP genes are given an ' $R p^{\prime}$ prefix and MRP genes have an ' $m R p$ ' prefix. The seven exceptions to this standard RP nomenclature are mostly genes originally named to reflect a mutant phenotype, for example, the string of pearls (sop) gene encodes RpS2 [61] and bonsai encodes $\mathrm{mRpS} 15[62,63]$. In these cases, the original gene symbol has been preserved, with the apposite RP symbol given as a synonym.

\section{Cytoplasmic ribosomal protein genes}

We identified 88 genes that encode a total of 79 different CRPs (Table 1). Thus, the D. melanogaster proteome contains orthologs of all 79 mammalian CRPs (32 small subunit and 47 large subunit proteins). While the majority of CRPs are encoded by single genes, nine are encoded by two distinct genes. In addition, we identified another five genes predicted to encode proteins with significantly lower similarity to human CRPs, which we term 'CRP-like' genes. Two fragments of the RpS6 gene were also identified. (The list of 88 CRP genes presented by Cherry et al. [64] originated from an earlier report of our results to FlyBase (MA and SJM, FBrfo178764). These authors also list five CRP-like genes from our original report, but two of these have been eliminated and two additional CRP-like genes have been added in the current analysis.)

The deduced characteristics of D. melanogaster and human CRPs are compared in Additional data file 1. As might be expected, the amino acid identity between the CRPs of the two species is very high (average of $69 \%$ with a range of $27-98 \%$, excluding the CRP-like proteins) and the predicted molecular 
Table I

The CRP genes of D. melanogaster

\begin{tabular}{|c|c|c|c|c|}
\hline \multirow[b]{2}{*}{ Human CRP } & \multicolumn{3}{|c|}{ D. melanogaster gene } & \multirow[b]{2}{*}{ BLAST E value } \\
\hline & Symbol* & CG number & Locationt & \\
\hline RPSA & sta/RpSA & CGI4792 & $X: 2 B I$ & $3 e-94$ \\
\hline RPS2 & sop/RpS2 & CG5920 & $2 \mathrm{~L}: 30 \mathrm{EI}$ & e-118 \\
\hline RPS3 & $R p S 3$ & CG6779 & 3R: 94E I3 & e- 106 \\
\hline RPS3A & $R p S 3 A$ & CG2168 & 4: IOIFI & e- 100 \\
\hline RPS4 & $R p S 4$ & CGII276 & $3 \mathrm{~L}: 69 \mathrm{~F} 6$ & $e-|2|$ \\
\hline \multirow[t]{2}{*}{ RPS5 } & $\mathrm{RpS5a}$ & CG8922 & $\mathrm{X}:$ I5E5-7 & le-98 \\
\hline & $R p S 5 b$ & CG70I4 & 3R: 88D6 & $3 e-96$ \\
\hline \multirow[t]{3}{*}{ RPS6 } & $R p S 6$ & CGI0944 & $\mathrm{X}: 7 \mathrm{C2}$ & e- 103 \\
\hline & CGII386 & CGII386 & $X: 7 C 2$ & $2 e-15$ \\
\hline & CG33222 & CG33222 & X: 7C2 & $2 e-15$ \\
\hline RPS7 & RpS7 & CGI883 & 3R: 99E2 & le-74 \\
\hline RPS8 & RpS8 & CG7808 & 3R: $99 \mathrm{C} 4$ & le-82 \\
\hline RPS9 & $R p S 9$ & CG3395 & 3L: 67BII & $8 e-92$ \\
\hline \multirow[t]{2}{*}{ RPSIO } & $R p S I O a$ & CGI 2275 & $3 R: 98 A \mid 4$ & $4 e-43$ \\
\hline & $R p S I O b$ & CGI4206 & $X: 18 D 3$ & $8 e-52$ \\
\hline RPSII & $R p S I I$ & CG8857 & 2R: 48E8-9 & le-58 \\
\hline RPSI2 & $R p S / 2$ & $C G \mid 127 I$ & 3L: 69F5 & $2 e-43$ \\
\hline RPSI3 & $R p S / 3$ & CGI3389 & 2L: 29B2 & $2 e-74$ \\
\hline \multirow[t]{2}{*}{ RPSI4 } & $R p S I 4 a$ & CGI524 & $x: 7 C 6-7$ & $3 e-7 \mid$ \\
\hline & $R p S I 4 b$ & CGI527 & X: 7C8 & $3 e-71$ \\
\hline RPSI5 & $R p S / 5$ & CG8332 & 2R: $53 C 8$ & $6 e-62$ \\
\hline \multirow[t]{2}{*}{ RPSI5A } & $R p S I 5 A a$ & CG2033 & $X: \mid I E I I-12$ & $2 e-65$ \\
\hline & $R p S I 5 A b$ & CGI 2324 & 2R: $47 \mathrm{Cl}$ & $6 e-65$ \\
\hline RPSI6 & $R p S I 6$ & CG4046 & $2 \mathrm{R}: 58 \mathrm{FI}$ & $2 e-69$ \\
\hline RPSI7 & $R p S I 7$ & CG3922 & $3 \mathrm{~L}: 67 \mathrm{~B} 5$ & $5 e-52$ \\
\hline RPSI8 & $R p S / 8$ & CG8900 & 2R: $56 \mathrm{FII}$ & $2 e-69$ \\
\hline \multirow[t]{2}{*}{ RPSI9 } & $\operatorname{RpS} 19 a$ & CG4464 & $\mathrm{X}: 14 \mathrm{~F} 4$ & $5 e-48$ \\
\hline & $R p S I 9 b$ & CG5338 & $3 \mathrm{R}: 95 \mathrm{Cl} 3$ & le-43 \\
\hline RPS20 & $R p S 20$ & CG15693 & 3R: 93AI & $7 e-50$ \\
\hline RPS2I & oho23B/RpS2I & CG2986 & 2L: $23 B 6$ & $3 e-30$ \\
\hline RPS23 & $R p S 23$ & CG84I5 & $2 \mathrm{R}: 50 \mathrm{E} 4$ & $8 e-70$ \\
\hline RPS24 & $R p S 24$ & CG375I & $2 \mathrm{R}: 58 \mathrm{~F} 3$ & $7 e-55$ \\
\hline RPS25 & $\operatorname{RpS} 25$ & CG6684 & 3R: 86D8 & le-38 \\
\hline RPS26 & $R p S 26$ & CGI0305 & 2L: $36 \mathrm{~F} 4$ & $3 e-47$ \\
\hline RPS27 & $R p S 27$ & CGI0423 & 3R: $96 \mathrm{C} 8$ & $2 e-39$ \\
\hline RPS27A & $R p S 27 A$ & CG527I & 2L: $3 \mid \mathrm{EI}$ & $8 e-80$ \\
\hline \multirow[t]{3}{*}{ RPS28 } & $R p S 28 a$ & CGI5527 & 3R: 99D2 & $|e-2|$ \\
\hline & $R p S 28 b$ & CG2998 & $X: 8 E 7$ & $2 e-23$ \\
\hline & RpS28-like & CG34/82 & $2 \mathrm{~L}: 30 \mathrm{~B} 3$ & le-07 \\
\hline RPS29 & $\operatorname{RpS} 29$ & CG8495 & 3R: 85E8 & $5 e-23$ \\
\hline RPS30 & $R p S 30$ & CGI5697 & $3 R: 93 A 2$ & $6 e-32$ \\
\hline RPLPO & RpLPO & CG7490 & 3L: 79B2 & e- 122 \\
\hline
\end{tabular}


Table I (Continued)

\begin{tabular}{|c|c|c|c|c|}
\hline & RpLP0-like & CGI38I & 2R: 46E5-6 & $3 e-10$ \\
\hline RPLPI & $R p L P I$ & CG4087 & $2 \mathrm{~L}: 2 \mathrm{IC2}$ & $3 e-34$ \\
\hline RPLP2 & $R p L P 2$ & CG49/8 & $2 R: 53 C 9$ & $5 e-32$ \\
\hline RPL3 & $R p L 3$ & CG4863 & 3R: 86D8 & 0.0 \\
\hline RPL4 & $R p L 4$ & CG5502 & 3R: 98B6 & $e-|4|$ \\
\hline RPL5 & $R p L 5$ & CGI 7489 & 2L: h35/40B & e- 120 \\
\hline RPL6 & RpL6 & CGII522 & 3R: $100 C 7$ & $8 e-58$ \\
\hline \multirow[t]{2}{*}{ RPL7 } & RpL7 & CG4897 & $2 \mathrm{~L}: 3|\mathrm{~B}|$ & $2 e-75$ \\
\hline & RpL7-like & CG53I7 & $2 \mathrm{~L}: 33 \mathrm{Cl}$ & $3 e-32$ \\
\hline RPL7A & $R p L 7 A$ & CG33/4 & $X: 6 B I$ & e- 102 \\
\hline RPL8 & $R p L 8$ & CGI 263 & $3 \mathrm{~L}: 62 \mathrm{E} 7$ & $e-119$ \\
\hline RPL9 & RpL9 & CG6/4I & $2 \mathrm{~L}: 32 \mathrm{Cl}$ & le-66 \\
\hline RPLIO & Qm/RpLIO & CGI $752 I$ & $3 \mathrm{~L}: \mathrm{h} 47 / 80 \mathrm{~A}$ & $7 e-98$ \\
\hline \multirow[t]{2}{*}{ RPLIOA } & $R p L I 0 A a$ & CG3843 & 3R: 88D 10 & $3 e-65$ \\
\hline & $R p L I O A b$ & CG7283 & $3 \mathrm{~L}: 68 \mathrm{EI}$ & $3 e-95$ \\
\hline RPLII & RpLIII & CG7726 & 2R: 56D7 & $6 e-83$ \\
\hline RPLI2 & $R p L I 2$ & CG3195 & $2 \mathrm{R}: 60 \mathrm{~B} 7$ & $7 e-75$ \\
\hline RPLI3 & RpLI3 & CG465I & $2 \mathrm{~L}: 30 \mathrm{~F} 3$ & le-68 \\
\hline RPLI3A & $R p L / 3 A$ & CGI475 & 3R: 83B6-7 & $3 e-68$ \\
\hline RPLI4 & $R p L / 4$ & CG6253 & 3L: 66D8 & $2 e-30$ \\
\hline RPLI5 & $R p L I 5$ & CGI 7420 & $3 \mathrm{~L}: \mathrm{h} 50-52 / 80 \mathrm{~F}$ & $5 e-90$ \\
\hline RPLI7 & RpLI 7 & CG3203 & $\mathrm{X}: 6 \mathrm{ClO}$ & $5 e-72$ \\
\hline RPLI8 & $R p L I 8$ & CG86/5 & $3 \mathrm{~L}: 65 \mathrm{E} 9$ & $3 e-71$ \\
\hline RPLI8A & $R p L I 8 A$ & CG6510 & $2 R: 54 C 3$ & $3 e-68$ \\
\hline RPLI9 & $R p L I 9$ & CG2746 & 2R: 60EII & $4 e-83$ \\
\hline RPL2I & RpL2I & CGI 2775 & $2 \mathrm{~L}: 40 \mathrm{~A}-\mathrm{B}$ & $4 e-66$ \\
\hline \multirow[t]{2}{*}{ RPL22 } & RpL22 & CG7434 & $\mathrm{X}: \mathrm{IC4}$ & $4 e-40$ \\
\hline & RpL22-like & CG987I & 2R: 59D3 & $2 e-24$ \\
\hline RPL23 & $R p L 23$ & CG366I & 2R: 59B3 & le-68 \\
\hline RPL23A & RpL23A & CG7977 & $3 \mathrm{~L}: 62 \mathrm{~A} 10$ & $7 e-52$ \\
\hline \multirow[t]{2}{*}{ RPL24 } & $R p L 24$ & CG9282 & 2L: $34 \mathrm{~B} 10$ & $7 e-55$ \\
\hline & RpL24-like & CG6764 & 3R: 86E5 & $8 e-14$ \\
\hline RPL26 & $R p L 26$ & CG6846 & 3L: 75E4 & $1 e-59$ \\
\hline RPL27 & $R p L 27$ & CG4759 & 3R: 96E9-10 & le-43 \\
\hline RPL27A & $R p L 27 A$ & CGI5442 & 2L: $24 \mathrm{~F} 3$ & $5 e-60$ \\
\hline RPL28 & $R p L 28$ & CGI 2740 & $3 \mathrm{~L}: 63 \mathrm{BI} 4$ & $3 e-31$ \\
\hline RPL29 & $R p L 29$ & CGI007I & 2R: 57D8 & $8 e-14$ \\
\hline RPL30 & $R p L 30$ & CGI0652 & 2L: 37B9 & $3 e-46$ \\
\hline RPL3I & RpL3I & CGI82I & 2R: $45 F 5$ & $5 e-47$ \\
\hline RPL32 & $R p L 32$ & CG7939 & 3R: 99D3 & $6 e-58$ \\
\hline \multirow[t]{2}{*}{ RPL34 } & RpL34a & CG6090 & $3 \mathrm{R}: 96 \mathrm{FIO}$ & $2 e-29$ \\
\hline & $R p L 34 b$ & CG9354 & 3R: 85DI5 & le-29 \\
\hline RPL35 & RpL35 & CG4III & X: 5AII & $2 e-38$ \\
\hline RPL35A & RpL35A & CG2099 & 3R: 83A4 & le-35 \\
\hline RPL36 & $R p L 36$ & CG7622 & $X:|B| 2$ & $3 e-33$ \\
\hline
\end{tabular}


Table I (Continued)

\begin{tabular}{|c|c|c|c|c|}
\hline RPL36A & $R p L 36 A$ & CG7424 & 2L: 28D3 & $3 e-43$ \\
\hline \multirow[t]{2}{*}{ RPL37 } & $R p L 37 a$ & CG909I & $X:|3 B|$ & $2 e-39$ \\
\hline & $R p L 37 b$ & CG9873 & 2R: $59 C 4$ & $|e-3|$ \\
\hline RPL37A & $R p L 37 A$ & CG5827 & 2L: $25 C 4$ & $2 e-38$ \\
\hline RPL38 & RpL38 & CGI800I & 2R: h46/4IC-E & $2 e-25$ \\
\hline RPL39 & RpL39 & CG3997 & 2R: $60 \mathrm{~B} 7$ & $3 e-18$ \\
\hline RPL40 & RpL40 & CG2960 & 2L: 24EI & $2 e-69$ \\
\hline RPL4I & RpL4I & CG30425 & 2R: 60E5 & $8 e-08$ \\
\hline
\end{tabular}

*Additional gene synonyms exist in most cases [60]. Bold font indicates CRP-like genes, putative pseudogenic fragments (CGI I 386 and CG33222) or the member of a duplicate gene pair that is expressed in a small number of tissues and/or at relatively low levels. †Computed cytological position is given for euchromatic genes (Genome Release 5 [60]). The cytological and h-band locations for heterochromatic genes are based on data in reference [15I] or estimated from images of in situ hybridizations of BACs to polytene chromosomes (RpL5 and RpL2I) [152]. The h-band location

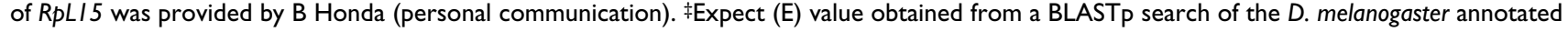
proteome (Genome Release 5.I) with human RefSeq CRP sequences. (E values corresponding to RpLI5 and RpS28-like were obtained from a BLAST search using Release 5.3.) Where multiple protein isoforms exist, the highest scoring hit is given.

weights and isoelectric points of the homologous proteins are very similar. However, several D. melanogaster proteins (RpL14, RpL22, RpL23A, RpL29, RpL34a, RpL34b, RpL35A) have significantly lower overall identity and different molecular weights owing to terminal deletions or extensions (data not shown; also see [65]). (If these seven proteins are discounted, the average identity of fly and human CRPs increases to $72 \%$ with a range of $43-98 \%$.) Similar to humans and other species, there are very few acidic CRPs in D. melanogaster: only six proteins (RpSA, RpS12, RpS21, RpLPo, RpLP1 and RpLP2) have isoelectric points less than $\mathrm{pH} 7$. (Note that RpS21 is an acidic protein, whereas its human counterpart is basic.) As in other eukaryotes, RpS27A and RpL40 are carboxyl extensions of ubiquitin [66-69], and, as in other animals, $\mathrm{RpS}_{3} \mathrm{O}$ is fused to a ubiquitin-like sequence. From these gross characterizations of component proteins, it appears that the fly cytoribosome differs only slightly from its human counterpart and is essentially the same as other eukaryotic cytoribosomes.

Previous biochemical analyses estimated that the D. melanogaster cytoribosome contains up to 78 CRPs [29]. This figure compares very well to the 79 different CRPs predicted by our orthology analysis (Table 1). Unfortunately, very few of the CRPs identified in the 1970 s and 1980 s were characterized to the level of amino acid sequence, so their correspondences to CRP genes are generally unknown, though there are a few exceptions (see references [70-73]). We have been unable, therefore, to correlate the CRPs identified in these earlier studies with those encoded by the CRP genes identified in this study. In contrast, our CRP inventory certainly does contain all 52 CRPs identified by the recent biochemical analysis of $D$. melanogaster cytoribosomes by Alonso and Santarén [34].

\section{Mitochondrial ribosomal protein genes}

We identified $75 \mathrm{D}$. melanogaster genes encoding proteins of the mitoribosome (28 in the small subunit and 47 in the large subunit) by orthology to human MRPs (Table 2). These data complement and extend previous analyses of homology between human and D. melanogaster MRPs [16,17]. As in these previous studies, genes encoding orthologs of three human MRPs (MRPS27, MRPS36 and LACTB/MRPL56) were not found.

The MRPs of humans and D. melanogaster are much more divergent than are their CRPs: MRPs have an average identity of only $34 \%$ (with a range of $15-57 \%$ ) and several homologous pairs differ markedly in their sizes and isoelectric points (Additional data file 2). Indeed, it is known that the mitoribosome is a rapidly evolving structure whose composition varies among eukaryotic organisms [6]. It is quite possible that there are proteins in Drosophila mitoribosomes that are not found in their human counterparts and these will have been missed by our orthology analysis - a definitive inventory will require biochemical characterization of the fly mitoribosome. As in mammals, three distinct genes encode three different isoforms of MRPS18 (Table 2); it is thought that each mitoribosome contains a single MRPS18 protein and that mitoribosomes may, therefore, be heterogeneous in composition [6].

\section{Duplicate cytoplasmic ribosomal protein genes}

Of the 79 different CRPs of D. melanogaster, 9 are encoded by two distinct genes (Table 1). These are distinguished by a lowercase ' $a$ ' or ' $b$ ' suffix to the gene symbol. (The lowercase ' $a$ ' should not be confused with the uppercase ' $A$ ' suffix used in the standard CRP nomenclature; for example, $R p L 37 a$ and $R p L 37 A$ are different genes that encode different proteins.) Six of these gene pairs encode proteins of the small ribosomal subunit and the other three encode large subunit proteins. In humans, each CRP is typically encoded by a single, functional gene $[37,74]$, but thousands of nonfunctional CRP pseudogenes are known to exist [75]. We therefore investigated the evolutionary origin, sequence conservation and expression 
Table 2

The MRP genes of $D$. melanogaster

\begin{tabular}{|c|c|c|c|c|}
\hline \multirow[b]{2}{*}{ Human MRP } & \multicolumn{3}{|c|}{ D. melanogaster gene } & \multirow[b]{2}{*}{ BLAST E value: } \\
\hline & Symbol* & CG number & Location' & \\
\hline MRPS2 & $m R p S 2$ & CG2937 & $2 \mathrm{~L}: 25 \mathrm{BI}$ & le-69 \\
\hline MRPS5 & $m R p S 5$ & CG40049 & 3L: h47/80A-B & $4 e-63$ \\
\hline MRPS6 & $m R p S 6$ & CGI5016 & 3L: 64B2 & $2 e-20$ \\
\hline MRPS7 & $m R p S 7$ & CG5 108 & 2L: 3IDII & $6 e-38$ \\
\hline MRPS9 & $m R p S 9$ & CG2957 & 3R: 84E4 & $8 e-81$ \\
\hline MRPSIO & $m R p S I 0$ & CG4247 & 3R: 88E3 & le-33 \\
\hline MRPSII & $m R p S I I$ & CG5/84 & 3R: 89EII & $8 e-26$ \\
\hline MRPSI 2 & $t k o / m R p S I 2$ & CG7925 & $X: 3 A 3$ & le-33 \\
\hline MRPSI4 & $m R p S / 4$ & CG3253I & $X: 18 C 7$ & le-35 \\
\hline MRPSI5 & bonsai/mRpSI5 & CG4207 & $2 \mathrm{R}: 58 \mathrm{~F} 3$ & Ie-I5 \\
\hline MRPSI 6 & $m R p S I 6$ & CG8338 & 2R: $50 \mathrm{EI}$ & $2 e-24$ \\
\hline MRPSI7 & $m R p S I 7$ & CG4326 & $2 \mathrm{R}: 60 \mathrm{Cl}$ & $2 e-14$ \\
\hline MRPSI8A & $m R p S I 8 A$ & CG3/450 & $3 R: 85 A 3$ & $8 e-13$ \\
\hline MRPSI8B & $m R p S I 8 B$ & CGI0757 & 2L: $38 B 6$ & $4 e-33$ \\
\hline MRPSI8C & $m R p S I 8 C$ & CG9688 & 3R: 99F4 & $7 e-23$ \\
\hline MRPS2I & $m R p S 2 I$ & CG32854 & 3R: 87E8 & $3 e-22$ \\
\hline MRPS22 & $m R p S 22$ & CGI226I & 3R: $98 \mathrm{~B} 6$ & $3 e-38$ \\
\hline MRPS23 & $m R p S 23$ & CG3/842 & 2L: 34D6 & $2 e-20$ \\
\hline MRPS24 & $m R p S 24$ & CGI3608 & 3R: 95E6 & $2 e-31$ \\
\hline MRPS25 & $m R p S 25$ & CGI44/3 & $\mathrm{X}: 12 \mathrm{FI}$ & le-49 \\
\hline MRPS26 & $m R p S 26$ & CG7354 & 3L: 75B9 & $3 e-11$ \\
\hline MRPS27 & NA & NA & NA & No hit \\
\hline MRPS28 & $m R p S 28$ & CG5497 & 2R: 55E2 & le-27 \\
\hline DAP3/MRPS29 & $m R p S 29$ & CG3633 & 2R: 58EI & $7 e-72$ \\
\hline MRPS30 & $m R p S 30$ & CG8470 & $X:|3 E| 8$ & $3 e-21$ \\
\hline MRPS3I & $m R p S 3 I$ & CG5904 & 3L: $72 \mathrm{C} 2$ & $5 e-35$ \\
\hline MRPS33 & $m R p S 33$ & CG10406 & 3R: $89 \mathrm{BI} 6$ & $3 e-30$ \\
\hline MRPS34 & $m R p S 34$ & CGI3037 & 3L: 72EI-2 & $8 e-06$ \\
\hline MRPS35 & $m R p S 35$ & CG2IOI & $3 \mathrm{~L}: 62 \mathrm{~F} 4$ & $2 e-72$ \\
\hline MRPS36 & NA & NA & NA & No hit \\
\hline MRPLI & $m R p L I$ & CG7494 & 3R: 84F9-10 & $8 e-25$ \\
\hline MRPL2 & $m R p L 2$ & CG7636 & 3L: 68A7 & $2 e-56$ \\
\hline MRPL3 & $m R p L 3$ & CG8288 & $X:|3 E| 4$ & $5 e-52$ \\
\hline MRPL4 & $m R p L 4$ & CG58/8 & 2L: $35 \mathrm{FI}$ & $6 e-70$ \\
\hline MRPL9 & $m R p L 9$ & CG3/478 & $3 \mathrm{R}: 88 \mathrm{FI}$ & $6 e-17$ \\
\hline MRPLIO & $m R p L I O$ & CGI/488 & 2L: 2 IB4 & $8 e-20$ \\
\hline MRPLII & $m R p L I I$ & CG335I & $3 R: 88 C 3$ & $4 e-29$ \\
\hline MRPLI 2 & $m R p L I 2$ & CG50/2 & $3 \mathrm{~L}: 66 \mathrm{E} 5$ & $2 e-13$ \\
\hline MRPLI 3 & $m R p L I 3$ & CGI0603 & 2L: 37BI & $2 e-47$ \\
\hline MRPLI4 & $m R p L I 4$ & CGI 4048 & $X: 3 A I$ & $3 e-31$ \\
\hline MRPLI5 & mRpLI5 & CG5219 & 3L: 77C3 & $4 e-74$ \\
\hline MRPLI 6 & $m R p L I 6$ & CG3109 & $\mathrm{X}: 2 \mathrm{BI} 4$ & $3 e-58$ \\
\hline MRPLI7 & $m R p L I 7$ & CGI3880 & 3L: $61 \mathrm{~B} 3$ & $8 e-21$ \\
\hline MRPLI8 & $m R p L I 8$ & CGI 2373 & 2R: $49 C 2$ & $3 e-22$ \\
\hline MRPLI9 & $m R p L I 9$ & CG8039 & $3 \mathrm{R}: 85 \mathrm{~A} 5$ & le-56 \\
\hline MRPL20 & $m R p L 20$ & CGI/258 & 3L: 69F5 & $8 e-21$ \\
\hline
\end{tabular}


Table 2 (Continued)

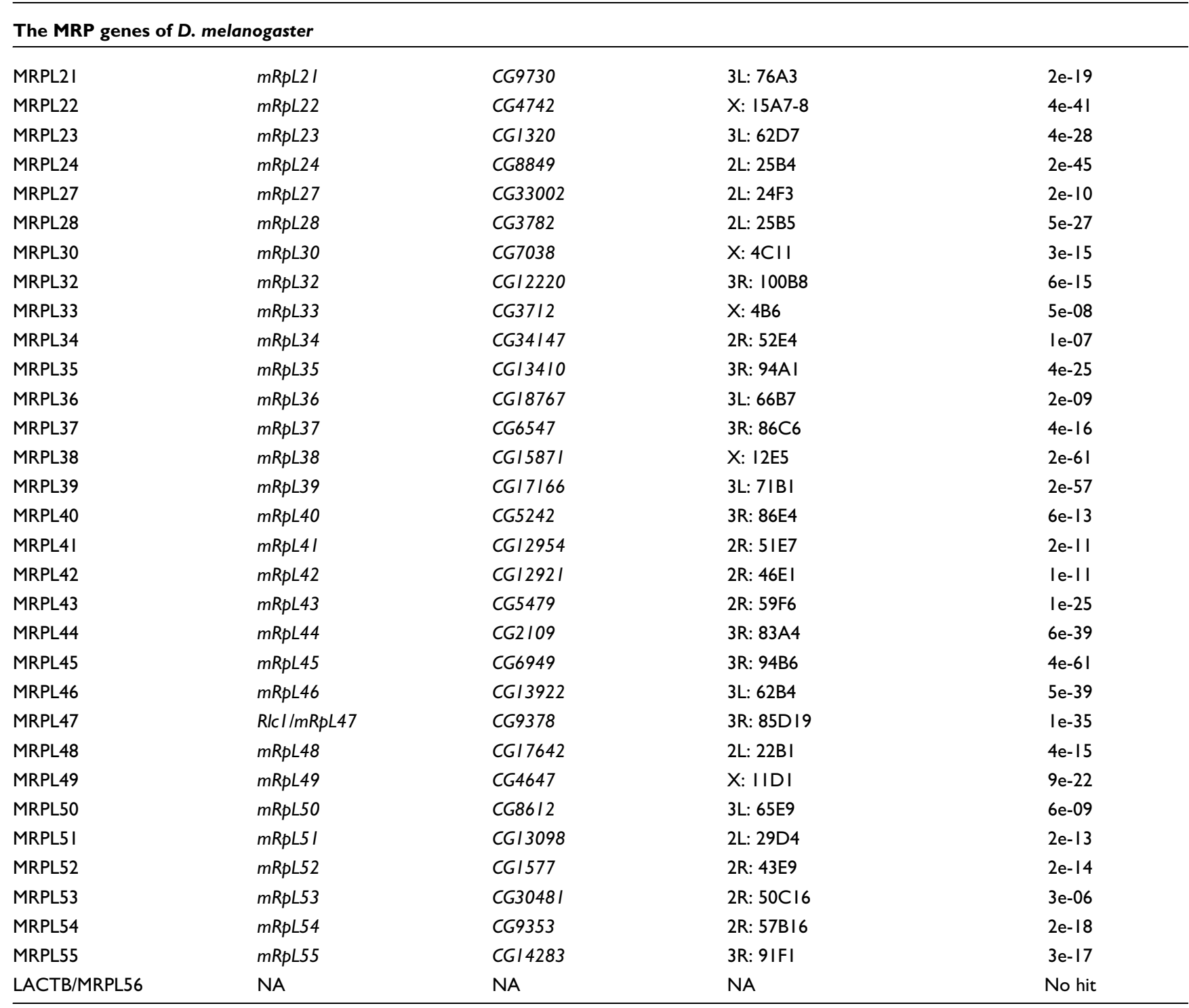

*Additional gene synonyms exist in many cases [60]. †Computed cytological position is given for euchromatic genes (Genome Release 5 [60]). mRpS5 h-band location provided by C Smith (DHGP, personal communication) and cytological position inferred from reference [15I]. $\neq$ Expect (E) value obtained from a BLASTp search of the D. melanogaster annotated proteome (Genome Release 5.I) with human RefSeq MRP sequences. Where multiple protein isoforms exist, the highest scoring hit is given.

profile of the duplicate $D$. melanogaster CRP genes in order to assess whether both members of each pair are likely to be functional (Table 3 and Figure 1).

In five cases, one member of the gene pair lacks introns (RpS1Oa, RpS15Ab, RpS28a, RpL1OAa and $R p L 37 b$ ) while the other member does not. These five intronless genes are likely to have arisen by retrotransposition; that is, generated via reverse transcription of mRNA from the precursor gene followed by insertion into a new genomic location. In contrast, the $R p S_{5}, R p S 19$ and $R p L 34$ duplicates arose through gene transposition events as both members of each pair retain introns. The $R p L 34$ duplication occurred through an intrachromosomal transposition on chromosome arm $3 \mathrm{R}$, and $R p L 34 a$ and $R p L 34 b$ have retained almost identical gene structures. In contrast, the $\mathrm{RpS}_{5}$ and $\mathrm{RpS} 19$ duplications involved interchromosomal transposition events that must have been followed by extensive gene remodeling as the intron-exon structures differ within each pair. Finally, $R p S 14 a$ and $R p S 14 b$ probably arose via unequal exchange: these paralogs are situated adjacent to each other as a tandem duplication on the $X$ chromosome, share identical intronexon structures and encode identical proteins [76]. All nine duplicate genes appear to have arisen within the Drosophilidae, albeit at different stages in the lineage leading to D. melanogaster (Figure 1).

Neither member of these 9 CRP gene pairs contains a nonsense mutation in the protein-coding region (data not shown), indicating that all 18 genes are potentially functional. 
Table 3

Analysis of duplicate CRP genes and CRP-like genes

\begin{tabular}{|c|c|c|c|c|c|c|c|c|}
\hline & \multicolumn{3}{|r|}{ Gene } & \multicolumn{2}{|c|}{$K_{A} / K_{S}^{b}$} & \multicolumn{2}{|c|}{ cDNA clones } & \multirow[b]{2}{*}{$\begin{array}{l}\% \text { Amino acid } \\
\text { identityg }\end{array}$} \\
\hline & Symbola & Location & Comments & Pair-wise ${ }^{c}$ & $\begin{array}{l}\text { Branch- } \\
\text { specific }^{d}\end{array}$ & Totale & $\%$ testis $^{f}$ & \\
\hline \multirow[t]{2}{*}{ RpS5 } & $\mathrm{RpS5a}$ & $X: 15 E 5-7$ & - & 0.07 & 0.09 & 133 & 1 & 78 \\
\hline & $R p S 5 b$ & 3R: 88D6 & - & & 0.09 & 60 & 7 & \\
\hline \multirow[t]{3}{*}{ RpS6 } & $R p S 6$ & $\mathrm{X}:$ 7C2 & - & NA & NA & 150 & 5 & $33^{\mathrm{h}}$ \\
\hline & CGII386 & $\mathrm{X}: 7 C 2$ & $\begin{array}{l}\text { CGI I } 386 \text { and CG33222 are tandem repeats of the } \\
\text { third exon and flanking regions of RpS6 }\end{array}$ & & NA & 0 & 0 & \\
\hline & CG33222 & $\mathrm{X}: 7 C 2$ & & & NA & 3 & 0 & \\
\hline \multirow[t]{2}{*}{$R p S I 0$} & RpSIOa & $3 R: 98 A \mid 4$ & Lacks introns; likely retrogene & 0.10 & 0.15 & 1 & 0 & 73 \\
\hline & $R p S I O b$ & $X: 18 D 3$ & - & & 0.01 & 156 & 0 & \\
\hline \multirow[t]{2}{*}{$R p S / 4$} & $R p S I 4 a$ & $\mathrm{X}: 7 C 6-7$ & $R p S / 4 a$ and $R p S / 4 b$ share identical gene structures & NA & NA & 154 & 2 & 100 \\
\hline & $R p S I 4 b$ & X: 7C8 & & & NA & 12 & 0 & \\
\hline \multirow[t]{2}{*}{$R p S I 5 A$} & $R p S I 5 A a$ & $X: \mid I E I I-I 2$ & - & 0.16 & 0.00 & 150 & 1 & 98 \\
\hline & $R p S I 5 A b$ & 2R: $47 \mathrm{Cl}$ & Lacks introns; likely retrogene & & NA & 67 & 1 & \\
\hline \multirow[t]{2}{*}{$R p S 19$} & $R p S 19 a$ & $\mathrm{X}: \mathrm{I4F} 4$ & - & 0.09 & 0.01 & 134 & 1 & 65 \\
\hline & $R p S I 9 b$ & $3 \mathrm{R}: 95 \mathrm{Cl} 3$ & - & & 0.08 & I & 100 & \\
\hline \multirow[t]{3}{*}{$\operatorname{RpS} 28$} & $R p S 28 a$ & 3R: 99D2 & Lacks introns; likely retrogene & 0.05 & 0.06 & 0 & 0 & 82 \\
\hline & $R p S 28 b$ & $\mathrm{X}: 8 \mathrm{E} 7$ & - & & 0.00 & 131 & 1 & \\
\hline & RpS28-like & 2L: $30 \mathrm{~B} 3$ & - & $\mathrm{NA}^{\mathrm{i}}$ & NA & 1 & 0 & $36 / 37 i$ \\
\hline \multirow[t]{2}{*}{ RpLPO } & $R p L P O$ & 3L: 79B2 & - & NA & NA & 157 & 2 & 18 \\
\hline & RpLP0-like & 2R: $46 \mathrm{E} 5-6$ & Present in all eukaryotes & & NA & 11 & 0 & \\
\hline \multirow[t]{2}{*}{ RpL7 } & RpL7 & $2 \mathrm{~L}: 3 \mid \mathrm{BI}$ & - & NA & NA & 168 & 4 & 30 \\
\hline & RpL7-like & $2 \mathrm{~L}: 33 \mathrm{Cl}$ & - & & NA & 32 & 0 & \\
\hline \multirow[t]{2}{*}{ RpLIOA } & $R p L I O A a$ & 3R: 88D 10 & Lacks introns; likely retrogene & 0.05 & 0.06 & 7 & 71 & 64 \\
\hline & $R p L I O A b$ & $3 \mathrm{~L}: 68 \mathrm{EI}$ & - & & 0.02 & 160 & 4 & \\
\hline \multirow[t]{2}{*}{ RpL22 } & RpL22 & $\mathrm{X}: \mathrm{IC4}$ & - & NA & NA & 145 & 2 & 38 \\
\hline & RpL22-like & 2R: 59D3 & - & & NA & 5 & 60 & \\
\hline \multirow[t]{2}{*}{ RpL24 } & RpL24 & 2L: $34 \mathrm{~B} 10$ & - & NA & NA & 162 & 3 & 23 \\
\hline & RpL24-like & 3R: 86E5 & Present in all eukaryotes & & NA & 34 & 3 & \\
\hline \multirow[t]{2}{*}{ RpL34 } & RpL34a & $3 \mathrm{R}: 96 \mathrm{FIO}$ & $R p L 34 a$ and $R p L 34 b$ share identical gene structures & 0.04 & 0.09 & 56 & 4 & 78 \\
\hline & $R p L 34 b$ & 3R: 85DI5 & & & 0.04 & 132 & 2 & \\
\hline \multirow[t]{2}{*}{ RpL37 } & RpL37a & $X:|3 B|$ & - & 0.01 & NA & 158 & 3 & 72 \\
\hline & $R p L 37 b$ & 2R: $59 \mathrm{C} 4$ & Lacks introns; likely retrogene & & 0.04 & 3 & $0^{k}$ & \\
\hline
\end{tabular}

aBold font indicates CRP-like genes, putative pseudogenic fragments (CGI/386 and CG33222) or the member of a duplicate gene pair that is expressed in a small number of tissues and/or at relatively low levels. ${ }^{b} K_{A} / K_{S}$ calculations are not applicable (NA) to highly diverged sequences or cases where the numbers of both synonymous and nonsynonymous substitutions are very small $(<5)$. ${ }^{c}$ Calculated for each $D$. melanogaster $C R P$ gene pair using maximum likelihood analysis. Values for pairwise comparisons are shown on the first row of each pair. ${ }^{B}$ Branch-specific score in a threeway maximum likelihood tree including $D$. pseudoobscura orthologs. A four-way tree was used for RpS 19 sequences. eTotal number of cDNA clones (excluding those from cultured cell lines) given in FlyBase [60] (April 2007). RpS28-like cDNA evidence from L Crosby (personal communication). fPercentage of cDNA clones from adult testis CDNA libraries (AT, UT and BS), rounded to the nearest integer. gldentity between proteins across their whole length. Values for pairwise comparisons are shown on the first row of each pair. hldentity between RpS6 and the CGII 386 or CG33222 protein. If CGI I 386 or CG33222 were used as alternative third exons of RpS6, the protein encoded would be $60 \%$ identical to the conventional RpS6 (see text for details). ${ }^{i} p \rho S 28$-like is too highly diverged from both $R p S 28 a$ and $R p S 28 b$ for a pair-wise $K_{A} / K_{S}$ calculation to be applicable. ildentity between the RpS28-like protein and RpS28a/RpS28b. ${ }^{~ T h e r e ~ i s ~ e x p e r i m e n t a l ~ e v i d e n c e ~ t h a t ~ R p L 37 b ~ e x p r e s s i o n ~ i s ~ e n r i c h e d ~ i n ~ a d u l t ~ t e s t i s ~[79] . ~}$

Moreover, the low ratio of nonsynonymous to synonymous substitutions $\left(K_{A} / K_{S}\right)$ between the members of each gene pair suggests that there are selective constraints on their proteincoding regions (Table 3 ; a $K_{A} / K_{S}$ ratio significantly lower than
0.5 indicates functional constraints on both genes). Branchspecific $K_{A} / K_{S}$ values further indicate that the putatively retrotransposed genes have been under overall purifying selection since their formation. Together, these data argue that 


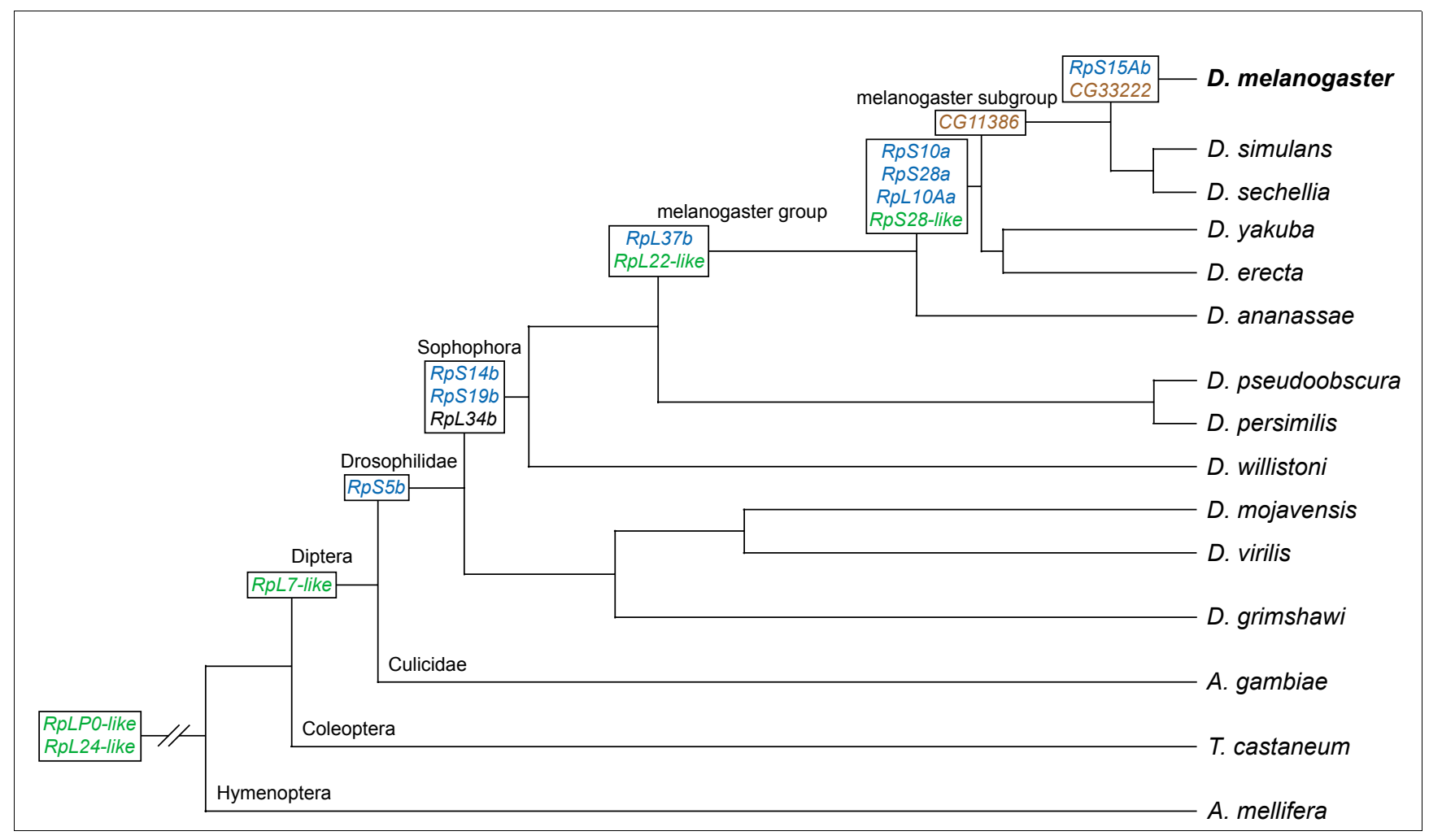

\section{Figure I}

Evolution of $D$. melanogaster CRP gene duplicates and CRP-like genes. The likely pattern of emergence of CRP duplicate genes with restricted expression (blue), CRP-like genes (green) and CRP pseudogenic fragments (brown) in the lineage leading to D. melanogaster is shown. RpL34b is shown in black text: this is the only case where the newly emerged duplicate gene (RpL34b), rather than precursor gene (RpL34a), acts as the principal gene copy. The relative placement of CGI I 386 and CG33222 is consistent with the model presented by Stewart and Denell [86]. The dendrogram is based on that given in reference [140], in which the relationships among the Drosophilidae are taken from [149]; note that the branch lengths do not accurately reflect evolutionary time.

none of these duplicate genes are nonfunctional pseudogenes, which is consistent with a previous analysis [77]. Indeed, the recovery of multiple cDNA clones for the majority (15/18) of these duplicate genes supports their expression in vivo (Table 3).

Although none of these CRP gene duplicates appear to be pseudogenes, it is evident that one member of each pair - the one with higher similarity to its human ortholog, where this difference exists (Table 1 and Additional data file 1) - is expressed at a significantly higher level and, in some cases, in a wider array of tissues than the other. This suggests that one gene of the pair produces the majority of each CRP in most cells, while the other gene has a more restricted expression pattern and, perhaps, a specialized function (indicated by bold font in Tables 1 and 3). In eight of the nine duplication events, the 'younger' gene copy has adopted the lower expression level or more restricted expression pattern; the $R p L 34$ gene pair is exceptional in this regard (Figure 1 and Table 3 ). The expression of $R p S 5 b, R p S 19 b, R p L 1 O A a$ and $R p L 37 b$ appears enriched in the adult testis, suggesting the existence of testis-specific CRPs and a testis-specific cytoribosome (Table 3). Significantly, three of these genes ( $R p S_{5} b, R p S_{19 b}$ and $R p L 37 b$ ), together with $R p S 1 O a, R p S 15 A b$ and $R p S 28 a$, are autosomal copies of $X$-linked genes. These duplication events are consistent with previous studies reporting that genes with male-biased expression are predominantly autosomal [78], and that retrotransposed genes in D. melanogaster have preferentially retrotransposed from the $X$ chromosome onto autosomes [79]. It is possible that these autosomal duplicates enable CRP expression in male germline cells, where it is hypothesized that $X$ chromosome inactivation occurs during spermatogenesis [80]. Similarly, in humans, $R P S 4 Y$ is a $Y$-linked duplicate of the $X$-linked $R P S 4$ gene [10] and RPL1OL, RPL36AL and RPL39L are autosomal retrogene copies of $X$-linked progenitors [74]. It is worth noting that expression of $D$. melanogaster $R_{p} S_{5} b, R_{p} S_{10 a}$ and $R p S 19 b$ is also enriched in the germline cells of embryonic gonads [81] and/or stem cells of adult ovaries [82]. These findings suggest a germline-specific role, rather than a testisspecific role, for these CRP gene duplicates.

To conclude, the 'principal' CRPs of D. melanogaster - those that are expressed at high levels in most cells - are each encoded by single genes. 


\section{Cytoplasmic ribosomal protein-like genes}

We identified five $D$. melanogaster 'CRP-like' genes that encode proteins with significantly lower identity to human CRPs than those described above. These are RpS28-like, RpLPo-like, RpL7-like, RpL22-like and RpL24-like (shown in bold font in Tables 1 and 3). Of these, RpLPo-like and RpL24like show the most divergence from their cognate proteins, RpLPo and RpL24. Consistent with this, RpLPo-like and $R p L 24-l i k e$ have ancient evolutionary origins, while $R p L 7-$ like, $R p L 22-l i k e$ and $R p S 28$-like arose more recently within the Diptera (Figure 1).

cDNA evidence indicates that all five of these CRP-like genes are expressed in vivo, albeit at far lower levels than their cognate genes (Table 3). The evolutionary conservation of RpLPo-like and RpL24-like suggests they have important cellular functions. Indeed, the yeast ortholog of RpL24-like is found in pre-ribosomal complexes where it is thought to function in large subunit biogenesis [83]. It remains to be seen whether the other CRP-like proteins have similar functions. Interestingly, the $R p L 22$ gene is $X$-linked and expressed ubiquitously, whereas $R p L 22-l i k e$ is an autosomal gene that is expressed predominantly in germline cells $[81,82,84,85]$. This suggests that RpL22-like may have a specialized role in the germline, and perhaps within germline-specific cytoribosomes, as proposed above for some of the CRP duplicates.

$C G 11386$ and $C G 33222$ are 99\% identical in DNA sequence and are tandem repeats of the third exon and flanking regions of the RpS6 gene. They likely arose via two sequential unequal crossover events [86]; the first occurring after the evolutionary split of the melanogaster subgroup, and the second being specific to D. melanogaster (Figure 1). Gene prediction algorithms suggest that $C G 11386$ and $C G 33222$ are distinct genes encoding identical amino-terminally truncated versions of RpS6 [87]; however, such proteins would lack critical functional domains and would probably be nonfunctional. In a different scenario, CG11386 and/or CG33222 could serve as alternative third exons of the RpS6 gene: the proteins produced would be full-length, but would differ substantially in their carboxy-terminal two-thirds from the RpS6 generated by using the conventional third exon [86]. There is, however, no direct evidence that such alternative transcripts are made. Indeed, only three cDNA clones suggest that CG11386 or CG33222 are expressed at all (Table 3). We have tentatively classified $C G 11386$ and $C G 33222$ as nonfunctional pseudogenic fragments.

\section{Chromosomal distribution of ribosomal protein genes} As has been found for other eukaryotes [35,36,38,39], the RP genes of $D$. melanogaster are distributed across the entire genome (Figure 2). Some RP genes are tightly linked to other RP genes and, while this posed challenges for determining the phenotypes associated with individual genes (see below), we have no evidence that this distribution has functional consequences or that closely linked RP genes are transcriptionally co-regulated. Five RP genes ( $R p L 5, Q m / R p L 10, R p L 15$, $R p L 38$, and $m R p S_{5}$ ) are located within heterochromatic regions, as are certain human MRP genes [38] and some Arabidopsis thaliana CRP genes [36]. As heterochromatin is generally associated with the silencing of gene expression [88], the regulation of these genes must have adapted to the heterochromatic environment in order for the encoded proteins to be expressed at sufficiently high levels to meet the demand for ribosome synthesis in the cell [89].

\section{Ribosomal protein gene haploinsufficiency and the Minute syndrome}

Classical genetic studies have defined more than fifty regions of the D. melanogaster genome that are haploinsufficient and associated with the dominant phenotypes of prolonged development and short, thin bristles - the Minute loci [2] (Figure 3). To date, only fifteen Minute loci have been tied unequivocally to molecularly defined genes and all of these encode RPs (reviewed in reference [2]; also see references [48-53]). It has not been clear, however, if all Minute loci correspond to RP genes, or whether Minute loci may correspond to both CRP and MRP genes. We have conducted a new survey of Minute loci in the $D$. melanogaster genome which, combined with our RP gene inventory, has now allowed us to assess these relationships systematically.

Recent large-scale projects have provided a wealth of new genetic reagents that enable the mapping of Minute loci with a precision unavailable only a few years ago. Hundreds of new deletions with molecularly defined breakpoints have been provided by the efforts of the DrosDel consortium [90,91], Exelixis, Inc. [92], and the Bloomington Drosophila Stock Center [92]. When combined with older deletions characterized primarily through polytene chromosome cytology, these deletions have increased euchromatic genome coverage to 96-97\%. In addition, transposable element insertions now exist within $0.5 \mathrm{~kb}$ of $57 \%$ of all genes (R Levis, personal communication), largely through the efforts of the Drosophila Gene Disruption Project [93] and Exelixis, Inc. [94]. We used

\footnotetext{
Figure 2 (see following page)

Chromosomal map of the RP genes of D. melanogaster. RP genes are depicted on a physical map of the genome (Release 5) [60]. Genes encoded on the positive and negative strands are shown above and below the chromosome, respectively. (The orientation of RpLI5 is not known and its position below the chromosome is arbitrary.) Chromosomes are divided into cytological bands as determined from sequence-to-cytogenetic band correspondence tables [150]. Minute genes are boxed as described in the key.
} 


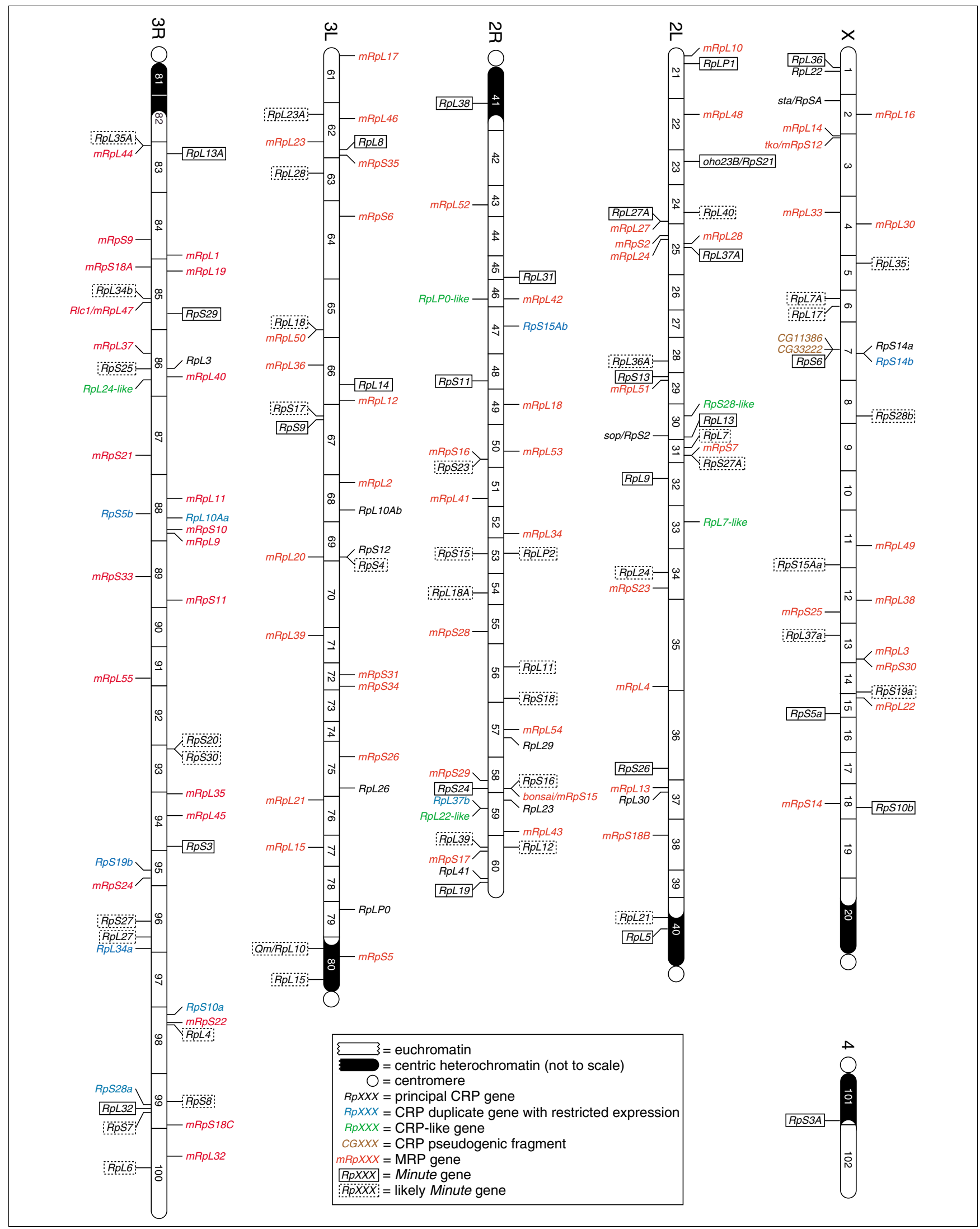

Figure 2 (see legend on previous page) 
these resources to conduct a genome-wide search for Minute loci. In so doing, we considered the characteristic Minute bristle phenotype (Figure 3) to be diagnostic of the Minute syndrome; we did not methodically evaluate more subtle Minute traits, such as slower development, or traits observed in only a subset of Minute mutants, such as impaired fecundity, reduced viability or altered body size. By combining our observations with information gleaned from published studies, we have identified 61 distinct Minute loci. Many of these correlate with Minute loci described previously (Additional data file 3 ), though our work has often refined their map positions. Significantly, six Minute loci (M(2)31E, M(2)34BC, $M(2) 45 F, M(2) 5 O E, M(3) 93 A$ and $M(3) 98 B)$ are reported here for the first time. We also found four instances (M(2)31A, M(2)53, M(2)58F and $M(3) 67 C)$ where a single Minute locus characterized by previous aneuploidy analyses actually comprises two separable, closely linked Minute genes. As we have inferred the existence of four additional Minute loci from patterns of deletion coverage (described below), we conclude that there are 65 distinct Minute loci in the D. melanogaster genome.

We were able to demonstrate definitively that a particular Minute locus corresponds to a specific RP gene when a Minute bristle phenotype was observed in one or more of the following situations: flies heterozygous for a molecularly characterized mutation in a RP gene (for example, $M(2) 36 F /$ $R p S 26)$; flies heterozygous for a chromosomal deletion when the Minute phenotype could be mapped unambiguously to a single RP gene with deletion breakpoints (for example, $M(2) 25 C / R p L 37 A$ ); or flies heterozygous for a chromosomal deletion when the Minute phenotype could be rescued by a specific RP transgene (for example, $M(3) 99 D / R p L 32)$. We found that there are 26 unequivocally Minute CRP genes by these criteria (Additional data file 4; summarized in Table 4). In contrast, no MRP or CRP-like genes were definitively demonstrated to be Minute genes.

These 26 cases of proven CRP gene-Minute locus correspondences provide a strong precedent for expecting that other CRP genes are also Minute genes. Although existing reagents do not allow us to demonstrate the correspondences definitively, we judged that a CRP gene very likely corresponds to a genetically defined Minute locus when one or more of the following criteria are fulfilled: a Minute phenotype is seen for a heterozygous multi-gene deletion that uncovers a single CRP gene (for example, $M(3) 63 B / R p L 28$ ); a CRP gene lies in a gap in deletion coverage and a molecularly uncharacterized Minute mutation maps to the same region (for example, $M(1) 8 F /$ $R p S 28 b$ ); or a CRP gene lies in a gap in deletion coverage and previous studies of transient aneuploids document the presence of a Minute locus in the same region (for example, $M(3) 99 E / R p S 7)$. In this way, we identified an additional 36 CRP genes that likely correspond to 34 genetically defined Minute loci (Additional data file 4; summarized in Table 4). Closely linked pairs of CRP genes map to the same regions as
$M(2) 6 o B$ and $M(3) 93 A$ and, as it was impossible to determine whether one or both genes of each pair are haploinsufficient, we have classified all four CRP genes as likely Minute genes. No CRP-like genes mapped to the regions of proven Minute loci. Although five MRP genes map to regions containing Minute loci, it is unlikely that any of them are haploinsufficient: MRP genes are not associated with Minute phenotypes in any other situation, and each of these five MRP genes is closely linked to a CRP gene (Additional data file 4).

We concluded that a further four CRP genes ( $R p L 17, R p L 18 A$, $R p L 34 b$ and $R p L 35 A$ ) are likely to be Minute genes despite no Minute phenotype having been associated with the genomic region in which they reside. In each of these cases, the CRP gene lies in a gap in deletion coverage (Table 4, Additional data file 4), suggesting that it is a Minute associated with strongly reduced fertility and/or viability, which prevents the establishment of stable deletion stocks (in the absence of a corresponding duplication). Supporting this view, such severe haploinsufficiency also appears to be associated with 15 other CRP genes - all these CRP genes lie in gaps in deletion coverage and they are only considered Minute genes here because they have point or transposon insertion (likely hypomorphic) mutations that cause Minute phenotypes, or because they lie in regions known to harbour Minute loci from the phenotypes of transient aneuploids (Table 4, Additional data file 4).

For all of the 40 CRP genes classified as 'likely Minute genes' (through correlation with genetically proven Minute loci or gaps in deletion coverage), we determined the maximum number of candidate genes that could possibly account for the haploinsufficiency. We used deletions to define the smallest chromosomal interval containing the Minute and then eliminated genes known not to be associated with a Minute phenotype from previous studies or from our own examinations of mutant fly strains. (This task benefited greatly from the recent work of the Bloomington Drosophila Stock Center which, in its efforts to maximize genomic deletion coverage, has systematically generated deletions flanking haploinsufficient loci.) The number of candidate genes defined in this way was always small, ranging from 2 to 33 genes with a median of 8.5 candidate genes per Minute locus (Table 4, Additional data file 4). These data increase our confidence in the likely correspondences between these Minute loci and CRP genes.

The results presented above indicate that 66 CRP genes are, or are likely to be, Minute genes, whereas the remaining 22 CRP genes are not (Table 4 and Additional data files 4 and 5; summarized in Figure 4). CRPs of the large and small ribosomal subunit are encoded by both Minute and nonMinute genes, with no apparent bias. Notably, none of the nine duplicate CRP genes with relatively restricted expression is a Minute, whereas seven of the more highly and widely expressed gene pair members are Minute genes. This is consistent with the idea that only one member of each of these 

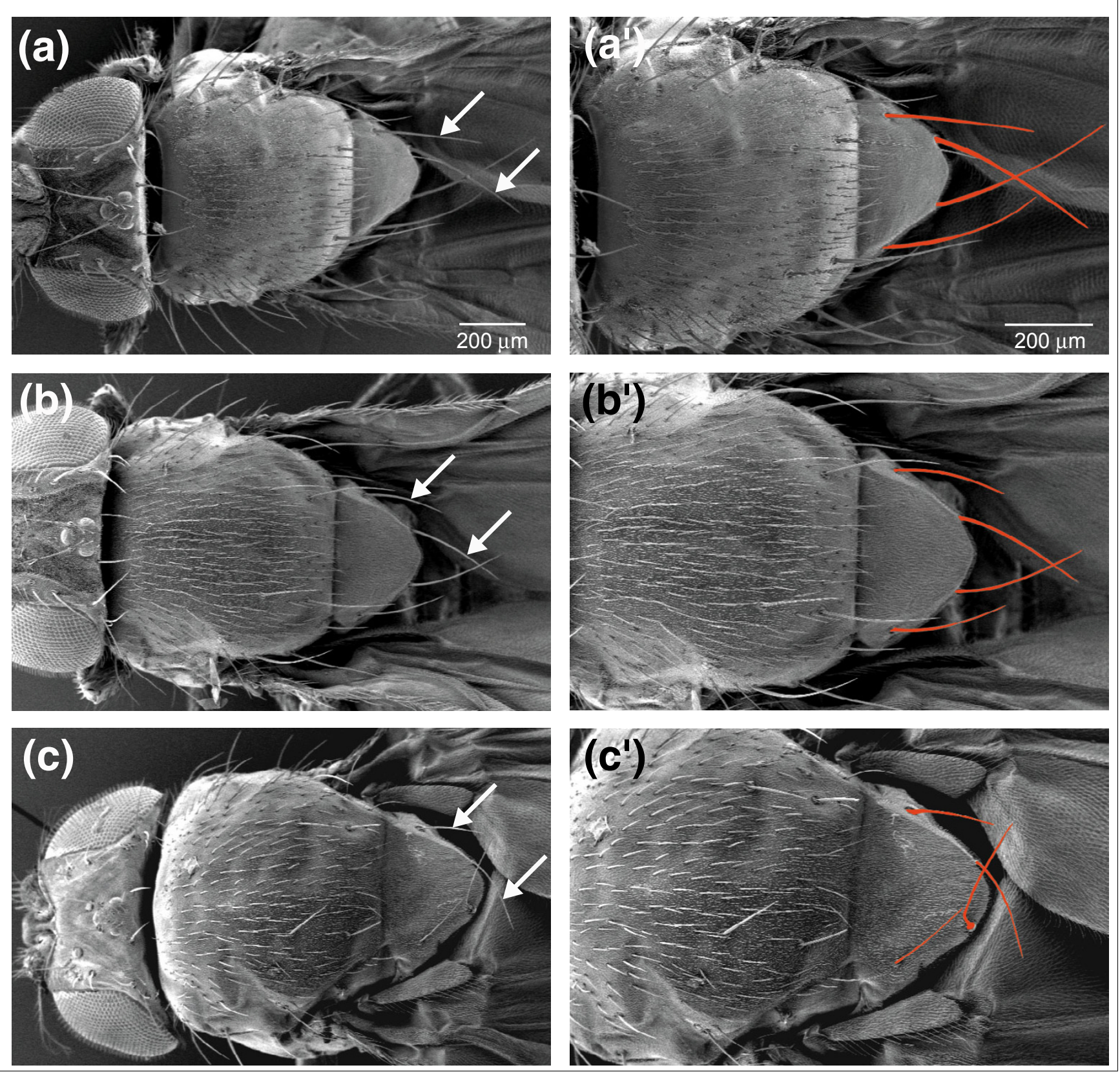

Figure 3

The Minute bristle phenotype. Minute flies have shorter and thinner bristles than wild type flies. This is most clearly seen by comparing the scutellar bristles, indicated here by the arrows and pseudocoloring. (a, $\left.\mathbf{a}^{\prime}\right)$ Wild type. (b, b') RpS/3' heterozygotes. (c, $\left.\mathbf{c}^{\prime}\right)$ RpLI $4^{\prime}$ heterozygotes.

gene pairs contributes significantly to cytoribosomal function in the majority of cells, while the one with restricted expression encodes a component of qualitatively distinct cytoribosomes in certain cell types. As the 'principal' copy of $R p S 14$ or $R p L 1 O A$ is not a Minute, it is unsurprising that the simultaneous heterozygous deletion of both $R p S 14$ genes [95] or both $R p L 10 A$ genes (in flies with genotypes $D f(3 L) E D 4475 /$ $D f(3 R) E D 10556$ or $D f(3 L) E D 4475 / D f(3 R) E D 5660$; our observations) does not produce flies with Minute phenotypes.
Other possible reasons for different dosage sensitivities among CRP genes are discussed below.

The one verified Minute locus that does not correspond to a CRP gene is $M(1) 14 C$. We mapped this Minute gene to region 14C6 by showing that the deletions $D f(1) E D 7364$ (14A8;14C6) and $D f(1) F D D-0230908$ (14C6;14E1) are each associated with a Minute phenotype. Moreover, we could rescue these phenotypes, as well as the Minute phenotype associated with 
Table 4

CRP gene haploinsufficiency

\begin{tabular}{|c|c|c|c|c|c|c|c|c|}
\hline \multicolumn{2}{|c|}{ CRP gene ${ }^{a}$} & \multicolumn{3}{|c|}{ Genetic analysis ${ }^{\mathrm{b}}$} & \multirow[b]{2}{*}{$\begin{array}{l}\text { Is the CRP } \\
\text { gene a } \\
\text { Minute? }\end{array}$} & \multirow[b]{2}{*}{$\begin{array}{l}\text { No. of } \\
\text { candidate } \\
\text { Minute } \\
\text { genesg }\end{array}$} & \multirow[b]{2}{*}{$\begin{array}{l}\text { Minute } \\
\text { synonym }\end{array}$} & \multirow[b]{2}{*}{ Reference $e^{i}$} \\
\hline Symbol & Location & $\begin{array}{c}\text { CRP gene } \\
\text { mutations } s^{c, d}\end{array}$ & $\begin{array}{l}\text { Deletions } \\
\text { removing a } \\
\text { single CRP } \\
\text { gene }^{\mathrm{c}, ~ e}\end{array}$ & Other evidence & & & & \\
\hline \multicolumn{9}{|l|}{ X chromosome } \\
\hline$R p L 36$ & $|B| 2$ & & $M$ & & Yes & & $M(I) I B$ & [53] \\
\hline RpL22 & IC4 & + & + & & No & & & \\
\hline sta/RpSA & $2 \mathrm{BI}$ & + & + & & No & & & \\
\hline$R p L 35$ & $5 \mathrm{All}$ & & & $\begin{array}{l}\text { Lies in a gap in deletion } \\
\text { coverage. } 5 \mathrm{~A} 6-13 \\
\text { aneuploids were Minute } \\
\text { (Merriam et al. [55]) }\end{array}$ & Likely & 33 & $M(I) 5 A$ & \\
\hline$R p L 7 A$ & $6 \mathrm{BI}$ & & $M$ & & Likely & 2 & $M(I) 5 D 6 A$ & \\
\hline RpLI 7 & $6 \mathrm{ClO}$ & & & $\begin{array}{l}\text { Lies in a gap in deletion } \\
\text { coverage }\end{array}$ & Likely & 12 & New? & \\
\hline RpS6 & $7 C 2$ & M & M & & Yes & & $\begin{array}{l}M(I) 7 B C \\
\text { and } M(I) 7 C\end{array}$ & [2] \\
\hline$R p S / 4 a$ & $7 C 6-7$ & & & $\begin{array}{l}\text { A deletion that removes } \\
R p S / 4 a \text { and } R p S / 4 b \text { is not } \\
\text { Minute [95] }\end{array}$ & No & & & \\
\hline$R p S I 4 b$ & $7 C 8$ & & & $\begin{array}{l}\text { A deletion that removes } \\
R p S / 4 a \text { and } R p S / 4 b \text { is not } \\
\text { Minute [95] }\end{array}$ & No & & & \\
\hline$R p S 28 b$ & $8 \mathrm{E} 7$ & & & $\begin{array}{l}\text { Lies in a gap in deletion } \\
\text { coverage. A Minute } \\
\text { mutation was mapped to } \\
\text { 8D8-9A2 [153] }\end{array}$ & Likely & 17 & $M(I) 8 F$ & \\
\hline$R p S I 5 A a$ & $|I E| I-12$ & & $M$ & & Likely & 8 & $M(I) I I F$ & \\
\hline$R p L 37 a$ & $|3 B|$ & & & $\begin{array}{l}\text { Lies in a gap in deletion } \\
\text { coverage. I2F6-I3B6 } \\
\text { aneuploids were Minute } \\
\text { (Merriam et al. [55]) }\end{array}$ & Likely & 2 & $M(I) / 3 A$ & \\
\hline$R p S / 9 a$ & I4F4 & & $M$ & & Likely & 14 & $M(I) / 4 E$ & \\
\hline$R p S 5 a$ & I5E5-7 & $M$ & & $\begin{array}{l}\text { Lies in a gap in deletion } \\
\text { coverage }\end{array}$ & Yes & & $M(I) / 5 D$ & [44] \\
\hline$R p S I O b$ & 18D3 & $M$ & $M$ & & Yes & & $M(I) / 8 C$ & \\
\hline \multicolumn{9}{|c|}{ Chromosome arm 2L } \\
\hline$R p L P I$ & $21 C 2$ & $M$ & $M$ & & Yes & & $M(2) 2 I C$ & {$[50]$} \\
\hline oho23B/RpS2I & $23 B 6$ & M & $M$ & & Yes & & $M(2) 23 B$ & [49] \\
\hline$R p L 40$ & $24 \mathrm{EI}$ & & $M$ & & Likely & 4 & $M(2) 24 D$ & \\
\hline RpL27A & $24 \mathrm{~F} 3$ & M & $M$ & & Yes & & $M(2) 24 F$ & \\
\hline$R p L 37 A$ & $25 \mathrm{C} 4$ & & $M$ & $\begin{array}{l}\text { The interval between } \\
\text { flanking non-Minute } \\
\text { deletions contains only } \\
\text { RpL37A }\end{array}$ & Yes & & $M(2) 25 C$ & \\
\hline$R p L 36 A$ & 28D3 & & $M$ & & Likely & 5 & $M(2) 28 D E^{*}$ & \\
\hline$R p S / 3$ & $29 \mathrm{~B} 2$ & M & M & & Yes & & $M(2) 29 B^{*}$ & {$[45]$} \\
\hline sop/RpS2 & $30 \mathrm{EI}$ & + & + & & No & & & \\
\hline$R p L I 3$ & $30 \mathrm{~F} 3$ & & M & $\begin{array}{l}\text { The interval between } \\
\text { flanking non-Minute } \\
\text { deletions contains only } \\
\text { RpLI3 }\end{array}$ & Yes & & $M(2) 3 / A$ & \\
\hline RpL7 & $3|B|$ & & $M$ & & Likely & 2 & $M(2) 3 / A$ & \\
\hline$R p S 27 A$ & $3|E|$ & & $M$ & & Likely & 6 & $M(2) 3 I E^{*}$ & \\
\hline
\end{tabular}


Table 4 (Continued)

\begin{tabular}{|c|c|c|c|c|c|c|c|c|}
\hline \multicolumn{9}{|c|}{ CRP gene haploinsufficiency } \\
\hline$R p L 9$ & $32 \mathrm{Cl}$ & $M$ & M & & Yes & & $M(2) 32 D$ & {$[46]$} \\
\hline RpL24 & $34 \mathrm{~B} 10$ & & $M$ & & Likely & 8 & $M(2) 34 B C^{*}$ & \\
\hline$R p S 26$ & $36 \mathrm{~F} 4$ & $M$ & M & & Yes & & $M(2) 36 F$ & \\
\hline$R p L 30$ & $37 B 9$ & + & + & & No & & & \\
\hline$R p L 2 I$ & $40 A-B$ & & M & & Likely & 10 & $M(2) 39 F$ & \\
\hline$R p L 5$ & $40 B$ & $M$ & M & & Yes & & $M(2) 40 B^{*}$ & {$[51]$} \\
\hline \multicolumn{9}{|c|}{ Chromosome arm 2R } \\
\hline$R p L 38$ & $4 I C-E$ & $M$ & M & & Yes & & $M(2) 4 I A$ & {$[51]$} \\
\hline RpL3I & $45 \mathrm{~F} 5$ & M & & $\begin{array}{l}\text { Lies in a gap in deletion } \\
\text { coverage }\end{array}$ & Yes & & $M(2) 45 F^{*}$ & \\
\hline$R p S I 5 A b$ & $47 \mathrm{Cl}$ & & + & & No & & & \\
\hline$R p S I I$ & $48 \mathrm{E} 8-9$ & $M$ & & $\begin{array}{l}\text { Lies in a gap in deletion } \\
\text { coverage }\end{array}$ & Yes & & $M(2) 48 E^{*}$ & \\
\hline $\operatorname{RpS} 23$ & $50 \mathrm{E} 4$ & & M & & Likely & 2 & $M(2) 50 E^{*}$ & \\
\hline$R p S I 5$ & $53 \mathrm{C} 8$ & & & $\begin{array}{l}M(2) 53 \text { I Minute phenotype } \\
\text { rescued by duplication of } \\
5 \text { IF-54A [I54] but not by a } \\
\text { RpLP2 transgene [155] }\end{array}$ & Likely & 16 & $M(2) 53$ & \\
\hline$R p L P 2$ & $53 \mathrm{C} 9$ & & M & & Likely & 5 & $M(2) 53$ & \\
\hline$R p L / 8 A$ & $54 C 3$ & & & $\begin{array}{l}\text { Lies in a gap in deletion } \\
\text { coverage }\end{array}$ & Likely & 16 & New? & \\
\hline RpLII & $56 \mathrm{D} 7$ & & & $\begin{array}{l}\text { Lies in a gap in deletion } \\
\text { coverage. 56C-D } \\
\text { aneuploids were Minute } \\
{[55]}\end{array}$ & Likely & 3 & $M(2) 56 C D$ & \\
\hline $\operatorname{RpS} 18$ & $56 \mathrm{FII}$ & & M & & Likely & 2 & $M(2) 56 F$ & \\
\hline RpL29 & 57D8 & & + & & No & & & \\
\hline$R p S I 6$ & $58 \mathrm{FI}$ & & & $\begin{array}{l}\text { Deletions that remove } \\
\text { both } R p S I 6 \text { and } R p S 24 \text { are } \\
\text { Minute. The Minute } \\
\text { mutations } M(2) 58 F^{I} \text { and } \\
\text { RpS24SH2053 complement, } \\
\text { suggesting RpSI } 6 \text { is a } \\
\text { Minute gene }\end{array}$ & Likely & 25 & $M(2) 58 F$ & \\
\hline $\operatorname{RpS} 24$ & $58 \mathrm{~F} 3$ & $M$ & & $\begin{array}{l}\text { Deletions that remove } \\
\text { both } R p S 16 \text { and } R p S 24 \text { are } \\
\text { Minute }\end{array}$ & Yes & & $M(2) 58 F$ & \\
\hline$R p L 23$ & $59 B 3$ & & + & & No & & & \\
\hline$R p L 37 b$ & $59 \mathrm{C} 4$ & & + & & No & & & \\
\hline RpLI 2 & $60 \mathrm{~B} 7$ & & & $\begin{array}{l}R p L I 2 \text { and } R p L 39 \text { lie in the } \\
\text { same gap in deletion } \\
\text { coverage. } 60 \mathrm{~B} 3-10 \\
\text { aneuploids were Minute } \\
{[156]}\end{array}$ & Likely & 9 & $M(2) 60 B$ & \\
\hline RpL39 & $60 \mathrm{~B} 7$ & & & $\begin{array}{l}R p L I 2 \text { and } R p L 39 \text { lie in the } \\
\text { same gap in deletion } \\
\text { coverage. } 60 \mathrm{~B} 3-10 \\
\text { aneuploids were Minute } \\
\text { [156] }\end{array}$ & Likely & 9 & $M(2) 60 B$ & \\
\hline RpL4I & $60 \mathrm{E} 5$ & + & + & & No & & & \\
\hline RpLI9 & $60 \mathrm{EII}$ & $M$ & & $\begin{array}{l}\text { A deletion that removes } \\
R p L / 9 \text { and } R p L 4 I \text { is Minute }\end{array}$ & Yes & & $M(2) 60 E$ & {$[42]$} \\
\hline \multicolumn{9}{|c|}{ Chromosome arm 3L } \\
\hline$R p L 23 A$ & $62 \mathrm{~A} 10$ & & M & & Likely & 8 & $M(3) 62 A$ & \\
\hline
\end{tabular}


Table 4 (Continued)

\begin{tabular}{|c|c|c|c|c|c|c|c|c|}
\hline \multicolumn{9}{|c|}{ CRP gene haploinsufficiency } \\
\hline$R p L 8$ & $62 \mathrm{E} 7$ & & & $\begin{array}{l}\text { Lies in a gap in deletion } \\
\text { coverage containing only } \\
\text { RpL8. 62E-63A aneuploids } \\
\text { were Minute [54] }\end{array}$ & Yes & & $M(3) 62 F$ & \\
\hline$R p L 28$ & $63 \mathrm{~B} \mid 4$ & & M & & Likely & 10 & $M(3) 63 B$ & \\
\hline RpLI8 & $65 \mathrm{E} 9$ & & M & & Likely & 8 & $M(3) 65 F$ & \\
\hline RpLI 4 & 66D8 & M & & $\begin{array}{l}\text { Lies in a gap in deletion } \\
\text { coverage }\end{array}$ & Yes & & $M(3) 66 D$ & [47] \\
\hline RpSI7 & 67B5 & & & $\begin{array}{l}\text { A deletion removing both } \\
R p S I 7 \text { and } R p S 9 \text { is Minute. } \\
\text { The unsequenced Minute } \\
\text { mutations } R p S I 7^{4} \text { and } \\
R p S I 7^{6} \text { complement the } \\
\text { Minute mutation } R p S 9 \text { EP } 3299 \text {, } \\
\text { suggesting } R p S I 7 \text { is a } \\
\text { Minute gene }\end{array}$ & Likely & 13 & $M(3) 67 C$ & \\
\hline RpS9 & $67 \mathrm{BII}$ & M & & $\begin{array}{l}\text { A deletion removing both } \\
R p S I 7 \text { and } R p S 9 \text { is Minute }\end{array}$ & Yes & & $M(3) 67 C$ & \\
\hline$R p L I O A b$ & $68 \mathrm{EI}$ & & + & & No & & & \\
\hline$R p S I 2$ & $69 \mathrm{~F} 5$ & & + & $\begin{array}{l}\text { A deletion that removes } \\
R p S / 2 \text { and } R p S 4 \text { is Minute }\end{array}$ & No & & & \\
\hline$R p S 4$ & $69 \mathrm{~F} 6$ & & & $\begin{array}{l}\text { A deletion that removes } \\
R p S 12 \text { and } R p S 4 \text { is Minute }\end{array}$ & Likely & 2 & $M(3) 69 E$ & \\
\hline$R p L 26$ & $75 \mathrm{E} 4$ & & + & & No & & & \\
\hline$R p L P O$ & 79B2 & + & + & & No & & & \\
\hline Qm/RpLIO & $80 \mathrm{~A}$ & & M & & Likely & 23 & $M(3) 80$ & \\
\hline RpLI5 & $80 \mathrm{~F}$ & & M & & Likely & $=11$ & $M(3) 80 F^{*}$ & \\
\hline \multicolumn{9}{|c|}{ Chromosome arm 3R } \\
\hline RpL35A & $83 \mathrm{~A} 4$ & & & $\begin{array}{l}\text { Lies in a gap in deletion } \\
\text { coverage }\end{array}$ & Likely & 3 & New? & \\
\hline$R p L I 3 A$ & 83B6-7 & $M$ & & $\begin{array}{l}\text { Lies in a gap in deletion } \\
\text { coverage }\end{array}$ & Yes & & $M(3) 83 B^{*}$ & [52] \\
\hline$R p L 34 b$ & $85 \mathrm{DI} 5$ & & & $\begin{array}{l}\text { Lies in a gap in deletion } \\
\text { coverage }\end{array}$ & Likely & 3 & New? & \\
\hline $\operatorname{RpS} 29$ & $85 \mathrm{E} 8$ & $M$ & $M$ & & Yes & & $M(3) 85 E$ & \\
\hline $\operatorname{RpS} 25$ & 86D8 & & & $\begin{array}{l}\text { A deletion that removes } \\
R p S 25 \text { and } R p L 3 \text { is Minute }\end{array}$ & Likely & 14 & $M(3) 86 D$ & \\
\hline RpL3 & 86D8 & + & & & No & & & \\
\hline$R p S 5 b$ & 88D6 & + & + & & No & & & \\
\hline$R p L I O A a$ & $88 \mathrm{DI} 0$ & & + & & No & & & \\
\hline$R p S 20$ & $93 \mathrm{Al}$ & & & $\begin{array}{l}\text { A deletion that removes } \\
R p S 20 \text { and } R p S 30 \text { is Minute }\end{array}$ & Likely & 21 & $M(3) 93 A^{*}$ & \\
\hline$R p S 30$ & $93 \mathrm{~A} 2$ & & & $\begin{array}{l}\text { A deletion that removes } \\
R p S 20 \text { and } R p S 30 \text { is Minute }\end{array}$ & Likely & 21 & $M(3) 93 A^{*}$ & \\
\hline$R p S 3$ & $94 \mathrm{EI} 3$ & $M$ & $M$ & & Yes & & $M(3) 95 A$ & [43] \\
\hline$R p S I 9 b$ & $95 \mathrm{Cl} 3$ & & + & & No & & & \\
\hline $\operatorname{RpS} 27$ & $96 \mathrm{C} 8$ & & $M$ & & Likely & 5 & $M(3) 96 C$ & \\
\hline$R p L 27$ & $96 \mathrm{E} 9-10$ & & $M$ & & Likely & 6 & $M(3) 96 C F$ & \\
\hline$R p L 34 a$ & $96 \mathrm{FIO}$ & & + & & No & & & \\
\hline$R p S I 0 a$ & $98 \mathrm{~A} / 4$ & & + & & No & & & \\
\hline RpL4 & $98 \mathrm{~B} 6$ & & $M$ & & Likely & 6 & $M(3) 98 B^{*}$ & \\
\hline RpS8 & $99 \mathrm{C} 4$ & & & $\begin{array}{l}\text { Lies in a gap in deletion } \\
\text { coverage. } 99 \mathrm{~B} \text { aneuploids } \\
\text { were Minute [157] }\end{array}$ & Likely & 11 & $M(3) 99 B$ & \\
\hline
\end{tabular}


Table 4 (Continued)

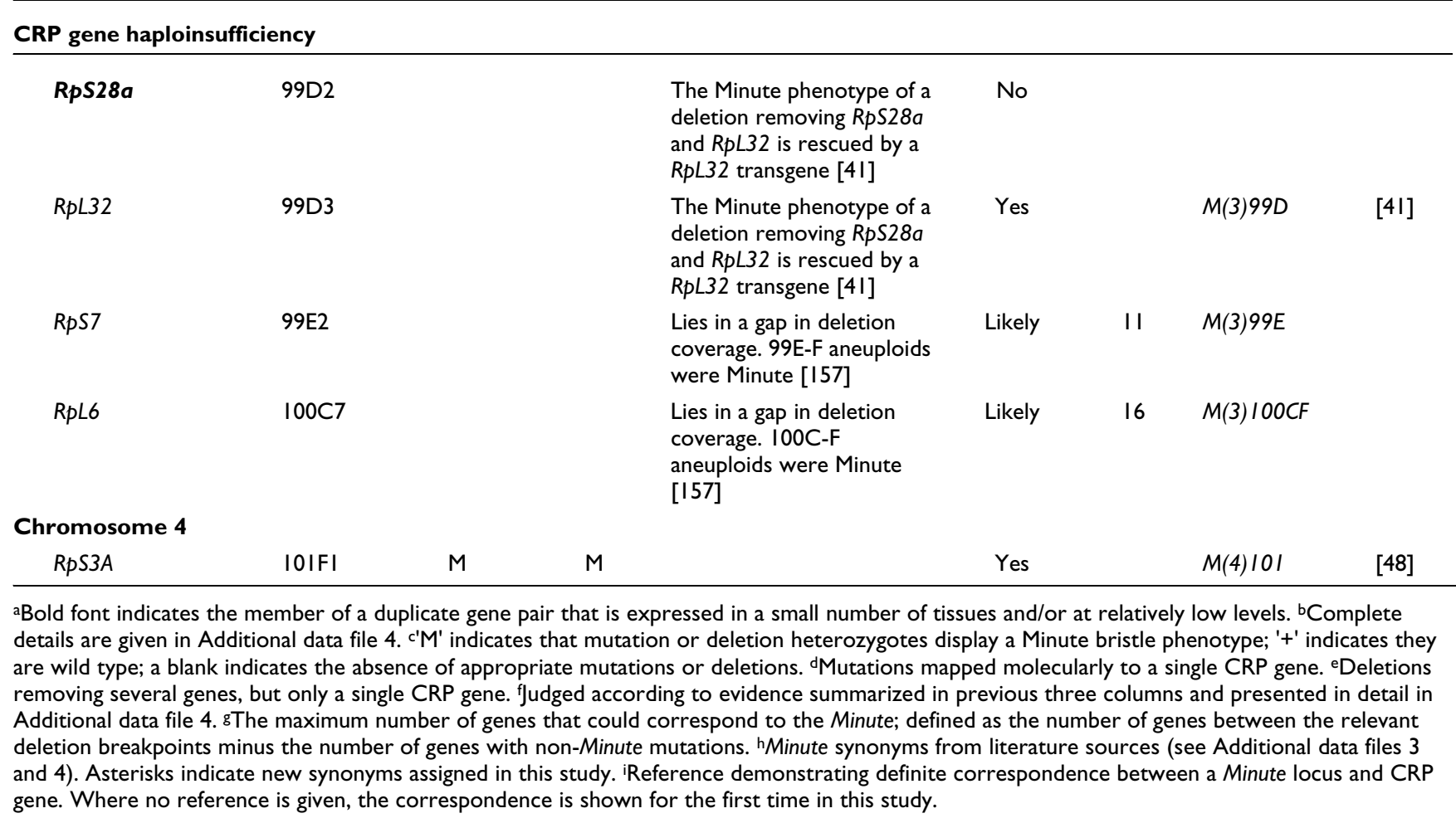

the $M(1) 14 C^{815-29}$ point mutation [44], using the small tandem duplication $D p(1 ; 1) F D D P-O 024486$ (14C4;14D1). The Minute region defined by these experiments contains only two genes: $C G 442 O$ and $e I F-2 \alpha$. Significantly, flies heterozygous for $P\left\{R S_{5}\right\} e I F-2 \alpha 5^{-H A-1790}$, an insertion in the $5^{\prime}$ untranslated region (UTR) of $e I F-2 \alpha$ that creates a likely hypomorphic allele, show a discernable, albeit weak Minute phenotype (our observations). This identifies $e I F-2 \alpha$ as $M(1) 14 C$. Consistent with this conclusion, flies expressing a dominant-negative eIF-2 $\alpha$ protein grow slowly and attain a small body size [96], phenotypes that are typical of the Minute syndrome. eIF- $2 \alpha$ is one of the three subunits that constitute eIF2, a key translation initiation factor that delivers the methionine-loaded initiator tRNA to the ribosome by transiently associating with the small cytoribosomal subunit [97]. Although eIF-2 $\alpha$ is not a component of cytoribosome complexes isolated by standard biochemical preparations, a reduction in $e I F-2 \alpha$ gene dosage might still be expected to adversely affect cytoribosomal function and decrease overall rates of protein synthesis by specifically impairing translation initiation.

Interestingly, the gene encoding eIF-2 $\gamma$, another subunit of the eIF2 translation initiation factor, is also haploinsufficient. Transcripts from the $S u(v a r) 3-9$ gene are alternatively spliced to produce two different proteins with distinct functions: one protein is the eIF-2 $\gamma$ translation factor, the other is responsible for suppression of position effect variegation [98]. Mutations that specifically eliminate the suppressor protein are homozygous viable and are not associated with Minute phenotypes [99], but deletions of the entire gene are haplolethal in the absence of $P\left\{\left(r y^{+}\right), 11.5 k b\right\}$, a transgenic construct carrying the complete $\mathrm{Su}$ (var)3-9 genomic region (our observations; Additional data file 6). These data indicate that the regions of the $S u$ (var)3-9 transcription unit encoding eIF-2 $\gamma$ are haplolethal. Moreover, it is possible that this haplolethality actually represents an extreme Minute phenotype associated with the $e I F-2 \gamma$-coding regions; hypomorphic $e I F$ $2 \gamma$ mutants, if isolated, may show less severe Minute phenotypes.

To assess the possibility that other translation factor genes might also be haploinsufficient/Minute, we examined the heterozygous loss-of-function phenotypes of 68 translation factor genes we identified from BLAST searches and/or Gene Ontology classification (Additional data file 6). We identified no other cases of haploinsufficiency, though five genes could not be assessed with existing deletion and mutation strains. In contrast to the genes encoding the other two subunits of $\mathrm{eIF} 2$, the $e I F-2 \beta$ gene is not haploinsufficient.

As mentioned above, we have compared our inventory of Minute genes with the Minute loci defined and named from previous genetic analyses (Additional data file 3). In so doing, we failed to validate the existence of several Minute loci described in the past, namely $M(1)_{3} E$ [55], $M(1) 4 B C$ [55], $M(2) 21 A B$ [100-102], $M(2) 44 C$ [55], M(3)76A [55], $M(3) 82 B C$ [55] and $M(3) 96 A$ [103]. The existence of some of 


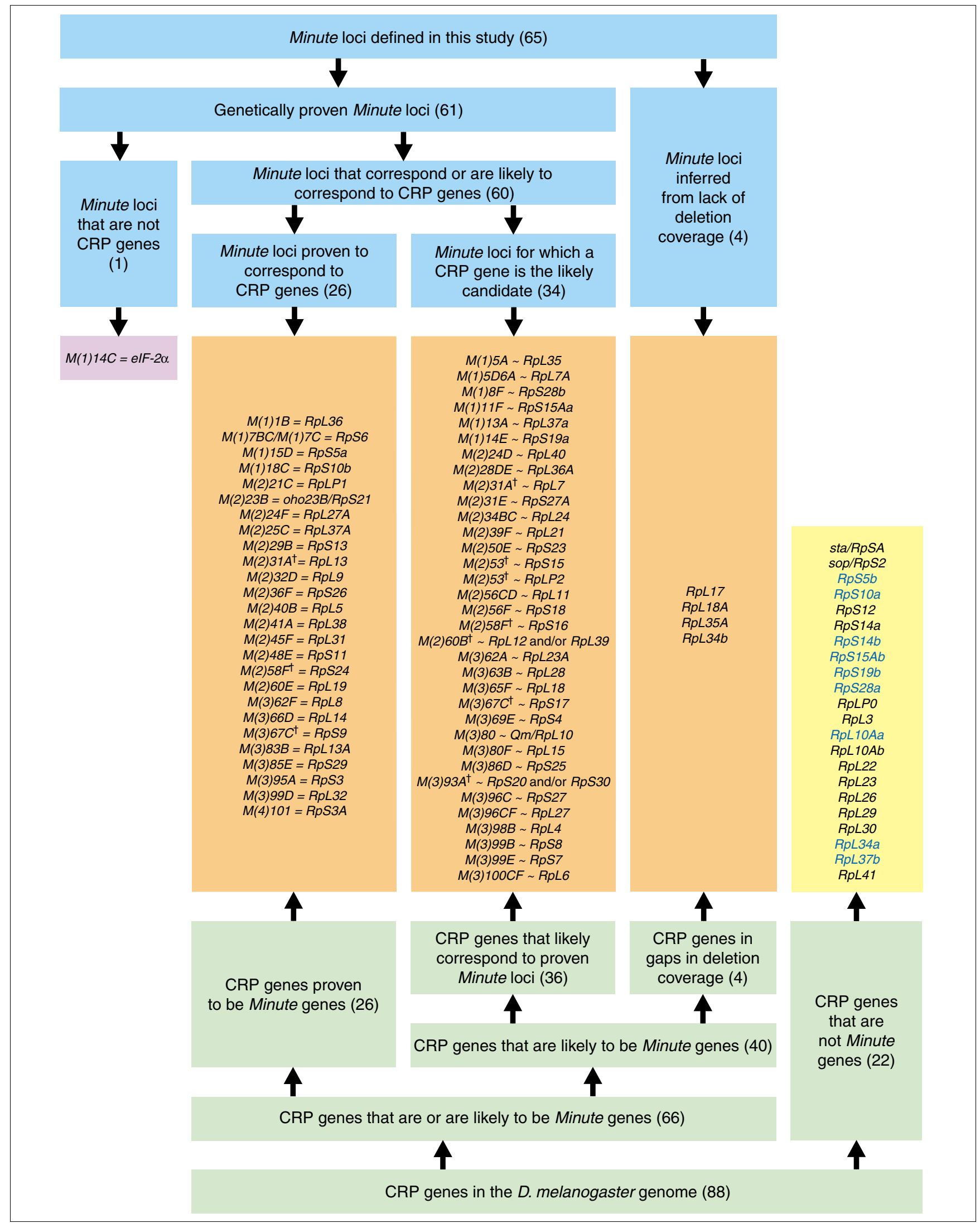

Figure 4 (see legend on next page) 
Figure 4 (see previous page)

Summary of Minute locus - CRP gene correspondences. This figure shows the relationship between Minute loci defined by genetic criteria and CRP genes identified using bioinformatics. ' $=$ ' indicates definite correspondence, ' $\sim$ ' indicates probable correspondence. Daggers mark Minute loci that we know or strongly suspect correspond to two CRP genes (as detailed in Table 4 and Additional data file 4).

these loci has been questioned previously and many cases appear to have involved chromosomal aberrations that were unusually complex or point mutations that were mismapped. Our failure to observe a Minute phenotype for deletions of $S$ adenosylmethionine synthetase (Sam-S), also known as $M(2) 21 A B$, is consistent with the phenotypic instability of dominant Sam-S mutations documented previously [100102]. This suggests that mutations in $S a m-S$ can phenocopy Minute mutations under certain conditions, but that $S a m-S$ is not a typical Minute gene.

In summary, CRP genes are likely to correspond to all but one of the 65 Minute loci defined in this study, with the sole exception encoding a translation initiation factor subunit (Figure 4). No MRP or CRP-like genes are unequivocally associated with a Minute phenotype, indicating that the Minute syndrome is specifically related to the function of the cytoribosomes responsible for the majority of cellular protein translation, rather than the function of specialized cytoribosomal variants. Twenty-five percent of CRP genes are not associated with an obvious haploinsufficient phenotype, clearly reinforcing previous findings that not all CRP genes are Minute genes [61,95,104].

\section{Discussion \\ CRP gene haploinsufficiency and the cytoribosome}

When one examines the phenotypes of flies carrying chromosomal deletions, one is struck by the remarkable tolerance of Drosophila to aneuploidy: flies heterozygous for deletions of hundreds of kilobases of DNA usually have no obvious dominant phenotypes. For this reason, the haploinsufficiency of single genes is all the more remarkable. It is even more striking that the vast majority of these haploinsufficient genes encode proteins of the cytoribosome and that haploinsufficiency is not apparent for genes encoding components of equally elaborate cellular complexes, such as mitoribosomes or spliceosomes. What accounts for the exquisite dosage sensitivity of CRP genes?

The primary cause of CRP gene haploinsufficiency is reasonably clear: halving the copy number of a CRP gene results in reduced mRNA expression of that CRP [105]. Similarly, depleting CRP mRNAs through antisense- or RNA interference (RNAi)-mediated approaches can also produce Minute phenotypes [106,107] (SJM and SJL, unpublished data). As there appear to be no compensatory increases in transcription [105], reducing dosages of CRP genes must result in reduced CRP protein levels in the absence of dramatic changes in mRNA stability or CRP protein turnover. How then does the reduction in the level of a single CRP result in impaired cytoribosomal function and reduced general protein synthesis, and how is this manifested as the Minute phenotype?

One possibility, termed the 'balance hypothesis' [108,109], is linked to the multisubunit nature of the cytoribosome. It posits that an imbalance in the concentrations of CRPs results in the assembly of incomplete and non-functional ribosomal subunits. Indeed, it is known that depletion of individual CRPs in Saccharomyces cerevisiae causes inefficient ribosomal subunit assembly and/or function [110,111]. Nevertheless, the balance hypothesis also predicts that overexpression of individual CRPs should cause stoichiometric imbalances and phenotypes similar to those produced by underexpression. This prediction is not upheld in either $S$. cerevisiae [112] or D. melanogaster [113]. Consequently, imbalance per se cannot account for the haploinsufficiency of CRP genes.

A simpler explanation of CRP haploinsufficiency is that a high concentration of cytoribosomes is required for proper cellular functions and that the cytoribosome population decreases sharply when the level of a single CRP is reduced. Cytoribosomes and their components do appear to be required in unusually high quantities: CRP mRNAs are among the most abundant cellular transcripts both in yeast [114] and in flies [6o], and can account for 50\% of all RNA polymerase IImediated transcription [89]. What seems critical, however, to the high-level production of fully formed cytoribosomes is that the concentration of each and every CRP never falls below a minimal level. In other words, cytoribosomal assembly is strictly limited by the availability of the least abundant component. This is probably not just a matter of simple selfassembly kinetics as improperly assembled ribosomal subunits and excess CRPs are actively degraded in yeast $[111,115]$. Similarly, RNAi-mediated depletion of single CRPs leads to the depletion of other CRPs in flies [64], suggesting the existence of similar degradation processes. Consequently, halving the supply of a single, limiting CRP is expected to halve the number of functional cytoribosomes. This may be tolerated by many cellular processes but will have severe effects wherever high protein synthesis is required, such as bristle formation and oocyte production in flies, or growth of $S$. cerevisiae in rich media [116]. It appears, therefore, that it is the combination of high demand for cytoribosomes and an assembly mechanism that assures that the level of the least abundant CRP determines the final concentration of cytoribosomes that makes CRP genes so exquisitely and specifically dosage sensitive. This perspective also provides a context for understanding the non-additivity of Minute mutations [117], where 
combinations of Minute mutations usually do not have a cumulative effect, but rather result in a phenotype similar to that of the most severe individual Minute mutant.

If adequate levels of cytoribosomes depend not so much on precise equimolar CRP concentrations as a minimal concentration of each and every CRP, then we should expect that variation in the expression of different CRPs (above the minimum level) might normally be tolerated in vivo. Such variation could be the result of differences in rates of gene transcription, mRNA translation, or mRNA/protein stability. This view provides a framework for understanding the spectrum of haploinsufficient phenotypes associated with CRP genes, which ranges from no obvious phenotypes, through bristle defects and reduced fecundity and viability, to dominant sterility or haplolethality in the most severe cases. That is, the severity of Minute phenotypes may be related to the rates at which individual CRPs are normally produced [105,106].

In reality, the explanation of CRP gene haploinsufficiency is probably more complicated than cytoribosome assembly relying simply on minimal CRP concentrations. The exact function, position or stoichiometry of CRPs within the cytoribosome may determine whether its gene is haploinsufficient and the severity of the Minute phenotype. For instance, our finding that the gene encoding the eIF-2 $\alpha$ translation initiation factor subunit is a Minute could indicate that haploinsufficient CRP genes encode ribosomal components involved specifically in translation initiation. As another example, RpLP1 and RpLP2 are the only CRPs required in two copies per cytoribosome [15] and, consequently, they must be produced at twice the level of all other CRPs. It is perhaps not surprising, therefore, that both $R p L P 1$ and $R p L P 2$ are haploinsufficient (Table 4) [50]. It may even be the case that the haploinsufficiency of some CRP genes arises by less conventional mechanisms. For example, the introns of 27 CRP genes host genes for small nucleolar RNAs (snoRNAs) [118-122], a class of non-coding RNAs that guide post-transcriptional modifications of rRNA molecules necessary for the maturation and incorporation of rRNA into ribosomes [123]. The expression of intronic snoRNAs depends upon the expression and processing of mRNAs from the host gene [124]. Consequently, mutations that reduce expression or splicing of CRP transcripts harboring snoRNAs will simultaneously deplete the cell of both a CRP and properly processed rRNA molecules, thereby impairing cytoribosome biogenesis in two different ways. Although 21 of the 27 CRP genes that carry snoRNA genes within their introns are Minute or likely Minute genes (data not shown), the presence of intronic snoRNA genes cannot be the sole factor determining CRP gene haploinsufficiency. Indeed, we have not found any single factor that clearly determines the degree of dosage sensitivity exhibited by different CRP genes.
Regardless of the exact causes and mechanisms of haploinsufficiency, it is pertinent to ask why the majority of CRPs are expressed so close to the level of sufficiency, such that loss of one gene copy is debilitating, rather than being synthesized in excess? One possibility concerns economics: cytoribosomal synthesis is an incredibly costly affair [89] and excessive CRP production would both be wasteful and monopolize the limited resources of the cell. A second possibility is that CRP levels are normally constrained to guard against inappropriate activation of cell growth, proliferation or apoptosis - processes in which CRPs and cytoribosomes have been postulated to play direct roles [125]. A final and intriguing possibility is that the barely sufficient expression levels of some CRP genes may have evolved as a viral defense mechanism. Cherry et al. [64] found that reducing the levels of 64 of the 79 principal CRPs by RNAi inhibits the propagation of Drosophila $\mathrm{C}$ virus in Drosophila adults and cultured cells. Because this virus requires high concentrations of cytoribosomes in its host cell to undergo efficient translation, tightly controlled expression of CRP genes at levels just sufficient for normal growth and development may protect against viral infection and provide a selective advantage. Interestingly, we found a modest correlation between a CRP gene being a Minute and it being able to inhibit virus replication in this assay. Clearly, further work will be required to test whether there is truly a relationship between normal CRP gene expression levels and susceptibility to viruses.

Minute mutations attracted the attention of early geneticists because they were isolated so often in D. melanogaster. In fact, Schultz said in 1929, "...so many have been found that this mutant type is one of the most frequent in Drosophila" [117]. As a considerable number of Minute mutants have also been isolated in other Drosophila species [6o], one might be justified in thinking Drosophila are unusually sensitive to CRP gene haploinsufficiency. On the other hand, the phenotypic consequences of CRP gene haploinsufficiency may simply be more noticeable in flies because they include conspicuous changes in external morphology. In fact, 'Minute-ness' may be a widespread phenomenon that is under-recognized because CRP gene haploinsufficiency has different and varied phenotypic consequences in other organisms. Recent research suggests this is the case [116,126-132]. For example, RPS5 haploinsufficiency disrupts cell division and causes developmental and growth phenotypes in Arabidopsis [126]; several CRP genes are haploinsufficient for suppression of nerve sheath tumors in zebrafish [127]; and RPS19 haploinsufficiency is a causative factor of DiamondBlackfan anemia in humans [128,130]. In fact, our reliance on the obvious bristle phenotype to distinguish Minute from non-Minute loci may present a biased assessment of CRP gene haploinsufficiency in the fly: it is quite possible that the 22 CRP genes classified as non-Minute in this study are associated with more subtle haploinsufficient phenotypes. How reduced CRP expression gives rise to diverse phenotypes is a mystery that, at least in part, reflects our current ignorance of 
the regulation and roles of CRPs in different cell types. This is certainly a topic worthy of more research.

\section{Conclusion}

We have assessed an idea that has been discussed for more than three decades; namely, that the haploinsufficient Minute loci of Drosophila correspond to the genes encoding protein components of ribosomes [2,133]. Our results confirm this idea and add important details. We have shown that Minute genes encode proteins of cytoplasmic ribosomes and not mitochondrial ribosomes, and we have defined the subset of CRP genes that are haploinsufficient. While duplicate genes encoding tissue-specific CRPs are not associated with Minute phenotypes, it is not otherwise clear what distinguishes the CRP genes that are haploinsufficient from those that are not. We identified a single Minute gene encoding a different kind of protein, a cytoplasmic translation initiation factor subunit. This hints that haploinsufficient CRP genes may encode proteins specifically involved in translation initiation, although further work is obviously needed to test this idea.

Minute genes account for the vast majority of the haploinsufficient genes in the $D$. melanogaster genome with effects on fertility and viability strong enough to prevent the recovery of chromosomal deletions in the absence of corresponding duplications. Indeed, there are very few additional genes (for example, $d p p$ [134], $A b d-B$ [135]) or chromosomal regions (for example, Tpl [136], wupA [137], Fs(1)1OA [138]) unequivocally associated with haplolethality or haplosterility. (A few other regions have been reported but not investigated in detail.) The most immediate practical use for our data will be in systematic efforts to maximize genome deletion coverage. Knowing which specific genes are haploinsufficient will make it feasible to flank each one as closely as possible with pairs of deletions, or to delete these genes in the presence of duplications or transgenic rescue constructs. Further improvements in deletion coverage will undoubtedly identify and map the remaining haplolethal or haplosterile loci.

Collectively, our inventories of the RP genes and Minute loci of D. melanogaster provide a solid foundation for further studies of RPs, ribosomes, and the causes and consequences of haploinsufficiency in flies and other organisms.

\section{Materials and methods Bioinformatics}

RefSeq human RP sequences were obtained from the National Center for Biotechnology Information [139]. The FlyBase BLASTp service [140] was used to identify high scoring hits from among the annotated proteins of D. melanogaster; tBLASTn was used when orthologs were not identified by a BLASTp search. The ExPASy proteomics server [141] was used to compute the average pI and molecular weight of the RPs. The percentage identity between human and $D$. melanogaster RP sequences or between $D$. melanogaster RP pairs was calculated using the NPS@ ClustalW alignment tool at the Pôle Bioinformatique Lyonnais using default parameters $[142,143] . K_{A} / K_{S}$ values were estimated using the program package PAML [144]. cDNA clone data were obtained from FlyBase [6o].

The identification of CRP gene orthologs and the plotting of their evolutionary emergence (Figure 1) were achieved using a combinatorial approach. First, sequences corresponding to the relevant CRP genes from D. melanogaster and Homo sapiens were used as queries in BLASTn, BLASTp, tBLASTn and BLAT searches of the genomes of other Drosophilid and insect species using the FlyBase BLAST server [140] and the UCSC Genome Bioinformatics BLAT server [145,146]. High scoring matches were judged to be potential orthologs and were analyzed further using the FlyBase OrthoView tool [87]. Second, the coding sequences (CDS) of relevant CRP genes from $D$. melanogaster and $H$. sapiens were used as queries in BLASTn searches of the GLEANR CDS prediction sets of other Drosophilid species [140]; phylogenetic trees were then generated from the high scoring matches, with the CDS of $S$. cerevisisae CRPs as roots, using the ClustalW tools at EMBLEBI [147]. Third, NCBI Homologene [148] was searched for any relevant homology calls: $R p L P o$-like, $R p L 7$-like and RpL24-like were found in HomoloGene clusters 102093, 64526 and 9462, respectively. The results of all these analyses were then compared, with the most parsimonious interpretations being used to annotate the dendrogram shown in Figure 1.

\section{Assessing Minute phenotypes and mapping Minute mutations}

In order to compile a list of all genetically defined Minute loci, we first catalogued all the Minute loci described in the fly literature $[2,54,55,60]$. We then inspected deletions for all genomic regions having deletion coverage to confirm or refute the existence of these Minute loci and to identify any new Minute loci that had previously gone undetected. Minute phenotypes were scored primarily by visual inspection of bristle length, although body size, developmental timing, fertility and viability were considered when information was available. Deletion-bearing flies were outcrossed to Oregon- $\mathrm{R}$ or Canton-S wild-type strains whenever we could not unambiguously score Minute phenotypes in stocks. The phenotypic effects of deleting or disrupting $X$-linked genes were assessed only in heterozygous females. Finally, the cytological locations of all verified Minute loci were correlated with the positions of RP genes to identify candidate genes.

To assess RP gene haploinsufficiency directly, we inspected flies heterozygous for deletions and/or mutations of molecularly identified RP genes. Minute phenotypes were scored as described above. For some deletions that had not been characterized molecularly, it was necessary to refine the mapping of breakpoints with complementation tests against 
molecularly mapped mutations or with polytene chromosome preparations to determine whether RP genes were deleted. (In a few cases, RP genes were classified as lacking deletion coverage when the only existing deletions were not useful in a practical sense owing to their associated chromosomal rearrangements or extremely large size.) A transposable element insertion was judged to disrupt a RP gene if it failed to complement other mutations in the gene, if we saw a Minute phenotype in the insertion strain, or if the transposon is inserted in the protein-coding region or 5 ' UTR of the gene based on FlyBase annotations [87] or our own BLAST analyses. (By these criteria, many nearby insertions, intronic insertions, and insertions in 3' UTRs were not used in our analysis.) We included molecularly characterized point mutations in our analyses for the few RP genes where they were available. Molecularly uncharacterized Minute point mutations from the Bloomington Stock Center were complementation tested against mutations and deletions known to disrupt or delete specific RP genes.

Fly strains were obtained from the Bloomington, Szeged, Kyoto and Harvard Drosophila Stock Centers. Helene Doerflinger and Daniel St Johnston provided $D f(3 R) I R 16$ and $D f(3 R) M R 22$ stocks, and Yuri Sedkov and Alexander Mazo provided $m R p L 16^{A}, m R p L 16^{B}$ and $m R p L 16^{C}$ stocks.

\section{Abbreviations}

CDS, coding sequence; CRP, cytoplasmic ribosomal protein; MRP, mitochondrial ribosomal protein; RNAi, RNA interference; RP, ribosomal protein; rRNA, ribosomal RNA; snoRNA, small nucleolar RNA; UTR, untranslated region.

\section{Authors' contributions}

SJM, JR, GR, AL and KRC conceived, designed and performed the experiments. SJM, MA, PH, ZY and KRC analyzed the data. JR, GR and KRC contributed fly strains. MA, GM and NK helped with gene classification and nomenclature. TCK and SJL provided funds, lab space and general support. SJM and KRC wrote the paper.

\section{Additional data files}

The following additional data are available with the online version of this paper. Additional data file 1 is a table comparing the physical characteristics of $D$. melanogaster and human CRPs, together with their RefSeq accession numbers. Additional data file 2 is a similar table comparing D. melanogaster and human MRPs. Additional data file 3 is a table listing all the Minute loci in a historical context. Additional data file 4 is a table showing our comprehensive genetic analyses of ribosomal protein gene haploinsufficiency. Additional data file 5 is a table listing CRP gene-Minute locus correspondences arranged in alpha-numerical order by RP gene symbol. Additional data file 6 is a table showing our genetic analyses of translation factor gene haploinsufficiency.

\section{Acknowledgements}

We would like to thank Bernard Mechler, Erika Viragh, Janos Szidonya, Chris Smith, Barry Honda, Don Sinclair, Kathleen Fitzpatrick, Mirelle Galloni, Lynn Crosby, Helene Doerflinger, Yuri Sedkov, Kathy Matthews and Phil East for data, assistance, helpful discussions or fly strains, and the Bloomington Drosophila Stock Center, the Szeged Drosophila Stock Centre, the Drosophila Genetic Resource Center at the Kyoto Institute of Technology, and the Exelixis Stock Collection at Harvard Medical School for providing the hundreds of strains used in this paper. Special thanks to Rachel Andrade, Kevin Bogart, Stacey Christensen, Jennifer Deal, Megan Deal and jill Gresens in Bloomington who generated many of the deletions that helped us map haploinsufficient loci with such precision. We also wish to thank Yuk Sang Chan and Terri Morley at the University of Cambridge for help with cytology and fly crosses, and Torill Rolfsen at the University of Oslo for the SEM pictures. SJM and SJL were funded by Cancer Research UK during this project. KRC and TCK were supported by a National Center for Research Resources grant (RROI4I06) and the Indiana Genomics Initiative. JR and MA were supported by an MRC Programme Grant (G8225539) and a European Union grant (QLRT-1999-30915). GR was supported by grants from the Deutsche Forschungsgemeinschaft (DFG Re9I I/3-2 and Re9I I/5-3) and the European Union (QLRI-CT-2000-009I5 and LSHG-CT 2000-503433). GM was supported by National Human Genome Research Institute grant HG000739. NK was funded by Grants-inAid for Scientific Research from the Ministry of Education, Culture, Sports, Science and Technology and the Japan Society for the Promotion of Science. PH and ZY were supported by a Discovery Grant from the Natural Sciences and Engineering Research Council of Canada.

\section{References}

I. Kay MA, Jacobs-Lorena M: Developmental genetics of ribosome synthesis in Drosophila. Trends Genet I987, 3:347-35I.

2. Lambertsson A: The Minute genes in Drosophila and their molecular functions. Adv Genet 1998, 38:69-134.

3. Wool IG: The structure and function of eukaryotic ribosomes. Annu Rev Biochem 1979, 48:719-754.

4. Harris EH, Boynton JE, Gillham NW: Chloroplast ribosomes and protein synthesis. Microbiol Rev 1994, 58:700-754.

5. Wool IG, Chan YL, Gluck A: Structure and evolution of mammalian ribosomal proteins. Biochem Cell Biol 1995, 73:933-947.

6. O'Brien TW: Properties of human mitochondrial ribosomes. IUBMB Life 2003, 55:505-5I3.

7. Brodersen $D E$, Nissen $P$ : The social life of ribosomal proteins. FEBS J 2005, 272:2098-2108.

8. Wool IG: Extraribosomal functions of ribosomal proteins. Trends Biochem Sci 1996, 21:164-165.

9. Draptchinskaia N, Gustavsson P, Andersson B, Pettersson M, Willig TN, Dianzani I, Ball S, Tchernia G, Klar J, Matsson H, et al:: The gene encoding ribosomal protein $\mathrm{SI9}$ is mutated in DiamondBlackfan anaemia. Nat Genet 1999, 2 I: 169-175.

10. Fisher EM, Beer-Romero P, Brown LG, Ridley A, McNeil JA, Lawrence JB, Willard HF, Bieber FR, Page DC: Homologous ribosomal protein genes on the human $X$ and $Y$ chromosomes: escape from $X$ inactivation and possible implications for Turner syndrome. Cell 1990, 63:1205-1218.

II. O'Brien TW, O'Brien BJ, Norman RA: Nuclear MRP genes and mitochondrial disease. Gene 2005, 354:|47-|5|.

12. Ruggero D, Pandolfi PP: Does the ribosome translate cancer? Nat Rev Cancer 2003, 3: I79-192.

13. Veuthey AL, Bittar G: Phylogenetic relationships of fungi, plantae, and animalia inferred from homologous comparison of ribosomal proteins. J Mol Evol 1998, 47:81-92.

14. Nakao A, Yoshihama M, Kenmochi N: RPG: the Ribosomal Protein Gene database. Nucleic Acids Res 2004, 32:DI68-I70.

I5. Wahl MC, Moller W: Structure and function of the acidic ribosomal stalk proteins. Curr Protein Pept Sci 2002, 3:93-I06.

16. Koc EC, Burkhart W, Blackburn K, Moseley A, Spremulli LL: The small subunit of the mammalian mitochondrial ribosome. Identification of the full complement of ribosomal proteins present. J Biol Chem 2001, 276:19363-19374.

17. Koc EC, Burkhart W, Blackburn K, Moyer MB, Schlatzer DM, Moseley 
A, Spremulli LL: The large subunit of the mammalian mitochondrial ribosome. Analysis of the complement of ribosomal proteins present. J Biol Chem 200I, 276:43958-43969.

18. HUGO Gene Nomenclature Committee [http:// www.genenames.org/]

19. Lambertsson AG, Rasmuson SB, Bloom GD: The ribosomal proteins of Drosophila melanogaster. I. Characterization in polyacrylamide gel of proteins from larval, adult, and ammonium chloride-treated ribosomes. Mol Gen Genet 1970, 108:349-357.

20. Lambertsson AG: The ribosomal proteins of Drosophila melanogaster. II. Comparison of protein patterns of ribosomes from larvae, pupae and adult flies by two-dimensional polyacrylamide gel electrophoresis. Mol Gen Genet 1972, I I 8:215-222.

21. Berger E: The ribosomes of Drosophila. I. Subunit and protein composition. Mol Gen Genet 1974, I 28: I-9.

22. Berger EM, Weber L: The ribosomes of Drosophila. II. Studies on intraspecific variation. Genetics 1974, 78: | |73-I I83.

23. Lambertsson AG: The ribosomal proteins of Drosophila melanogaster. 3. Further studies on the ribosomal protein composition during development. Mol Gen Genet 1974, I 28:24I-247.

24. Lambertsson AG: The ribosomal proteins of Drosophila melanogaster. IV. Characterization by two-dimensional gel electrophoresis of the ribosomal proteins from nine postembryonic developmental stages. Mol Gen Genet 1975, 139:133-144.

25. Vaslet C, Berger E: The ribosomes of Drosophila. IV. Electrophoretic identify among ribosomal subunit proteins from wild type and mutant $D$. melanogaster and $D$. simulans. Mol Gen Genet 1976, 147:189-194.

26. Weber L, Berger E, Vaslet C, Yedvobnick B: The ribosomes of Drosophila. III. RNA and protein homology between D. melanogaster and D. virilis. Genetics 1976, 84:573-585.

27. Berger E: The ribosomes of Drosophila. Normal and defective ribosome biosynthesis in Drosophila cell cultures. Mol Gen Genet 1977, 1 55:35-40.

28. Fekete E, Lambertsson A: Imaginal disc ribosomal proteins of $D$. melanogaster. Mol Gen Genet 1978, I 59:85-87.

29. Chooi WY, Sabatini LM, Macklin M, Fraser D: Group fractionation and determination of the number of ribosomal subunit proteins from Drosophila melanogaster embryos. Biochemistry 1980, 19:1425-1433.

30. Chooi WY: A comparison of the ribosomal proteins of Drosophila ovary, adult, and embryo. Mol Gen Genet I98I, I 84:342-346.

31. Kay MA, Jacobs-Lorena M: Selective translational regulation of ribosomal protein gene expression during early development of Drosophila melanogaster. Mol Cell Biol 1985, 5:3583-3592

32. Chooi WY: Purification of Drosophila ribosomal proteins. Isolation of proteins S8, SI3, SI4, SI6, S19, S20/L24, S22/L26, S24, S25/S27, S26, S29, L4, LI O/LI I, LI 2, LI 3, LI 6, LI 8, LI 9, L27, I, 7/8, 9, and I I. Biochemistry 1980, 19:3469-3476.

33. Chooi WY, Macklin MD, Leiby KR, Hong TH, Scofield SR, Sabatini LM, Burns DK: Purification of Drosophila acidic ribosomal proteins. Eur J Biochem 1982, I 27:199-205.

34. Alonso J, Santaren JF: Characterization of the Drosophila melanogaster ribosomal proteome. J Proteome Res 2006, 5:2025-2032.

35. Planta RJ, Mager WH: The list of cytoplasmic ribosomal proteins of Saccharomyces cerevisiae. Yeast 1998, 14:47I-477.

36. Barakat A, Szick-Miranda K, Chang IF, Guyot R, Blanc G, Cooke R, Delseny $M$, Bailey-Serres J: The organization of cytoplasmic ribosomal protein genes in the Arabidopsis genome. Plant Physiol 200I, 127:398-4I5.

37. Kenmochi N, Kawaguchi T, Rozen S, Davis E, Goodman N, Hudson TJ, Tanaka T, Page DC: A map of $\mathbf{7 5}$ human ribosomal protein genes. Genome Res 1998, 8:509-523.

38. Kenmochi N, Suzuki T, Uechi T, Magoori M, Kuniba M, Higa S, Watanabe K, Tanaka $\mathrm{T}$ : The human mitochondrial ribosomal protein genes: mapping of $\mathbf{5 4}$ genes to the chromosomes and implications for human disorders. Genomics 2001, 77:65-70.

39. Uechi T, Tanaka T, Kenmochi N: A complete map of the human ribosomal protein genes: assignment of 80 genes to the cytogenetic map and implications for human disorders. Genomics 200I, 72:223-230.

40. Yoshihama M, Uechi T, Asakawa S, Kawasaki K, Kato S, Higa S, Maeda $\mathrm{N}$, Minoshima S, Tanaka T, Shimizu N, Kenmochi N: The human ribosomal protein genes: sequencing and comparative anal- ysis of 73 genes. Genome Res 2002, I 2:379-390.

41. Kongsuwan K, Yu Q, Vincent A, Frisardi MC, Rosbash M, Lengyel JA, Merriam J: A Drosophila Minute gene encodes a ribosomal protein. Nature 1985, 3 17:555-558.

42. Hart K, Klein T, Wilcox M: A Minute encoding a ribosomal protein enhances wing morphogenesis mutants. Mech Dev 1993, 43: $101-110$.

43. Andersson S, Saeboe-Larssen S, Lambertsson A, Merriam J, JacobsLorena M: A Drosophila third chromosome Minute locus encodes a ribosomal protein. Genetics 1994, I37:5 I3-520.

44. McKim KS, Dahmus JB, Hawley RS: Cloning of the Drosophila melanogaster meiotic recombination gene mei-2 I8: a genetic and molecular analysis of interval I5E. Genetics 1996, 144:215-228.

45. Saeboe-Larssen S, Lambertsson A: A novel Drosophila Minute locus encodes ribosomal protein SI3. Genetics 1996, 143:877-885.

46. Schmidt A, Hollmann M, Schafer U: A newly identified Minute locus, M(2)32D, encodes the ribosomal protein L9 in Drosophila melanogaster. Mol Gen Genet 1996, 25 I:38I-387.

47. Saeboe-Larssen S, Urbanczyk Mohebi B, Lambertsson A: The Drosophila ribosomal protein LI4-encoding gene, identified by a novel Minute mutation in a dense cluster of previously undescribed genes in cytogenetic region 66D. Mol Gen Genet 1997. 255:|14|-|5|.

48. van Beest M, Mortin M, Clevers H: Drosophila RpS3a, a novel Minute gene situated between the segment polarity genes cubitus interruptus and dTCF. Nucleic Acids Res 1998, 26:447| -4475 .

49. Torok I, Herrmann-Horle D, Kiss I, Tick G, Speer G, Schmitt R, Mechler BM: Down-regulation of RpS2I, a putative translation initiation factor interacting with $\mathrm{P} 40$, produces viable Minute imagos and larval lethality with overgrown hematopoietic organs and imaginal discs. Mol Cell Biol 1999, 19:2308-232I.

50. Fauvarque MO, Laurenti $P$, Boivin A, Bloyer S, Griffin-Shea R, Bourbon HM, Dura JM: Dominant modifiers of the polyhomeotic extra-sex-combs phenotype induced by marked $P$ element insertional mutagenesis in Drosophila. Genet Res 200I, 78: $137-148$

5I. Marygold SJ, Coelho CM, Leevers S): Genetic analysis of RpL38 and $R p L 5$, two Minute genes located in the centric heterochromatin of chromosome 2 of Drosophila melanogaster. Genetics 2005, 169:683-695.

52. Alexander SJ, Woodling NS, Yedvobnick B: Insertional inactivation of the LI3a ribosomal protein gene of Drosophila melanogaster identifies a new Minute locus. Gene 2006, 368:46-52

53. Tyler DM, Li W, Zhuo N, Pellock B, Baker NE: Genes affecting cell competition in Drosophila. Genetics 2007, 175:643-657.

54. Lindsley DL, Sandler L, Baker BS, Carpenter AT, Denell RE, Hall JC Jacobs PA, Miklos GL, Davis BK, Gethmann RC, et al.: Segmental aneuploidy and the genetic gross structure of the Drosophila genome. Genetics 1972, 71:157-184.

55. Lindsley DL, Zimm GG: The Genome of Drosophila melanogaster San Diego, California: Academic Press; 1992.

56. Stewart B, Merriam JR: Segmental aneuploidy of the $\mathbf{X}$-chromosome. Drosophila Information Service 1973, 50:167-170.

57. The Bloomington Drosophila Stock Center: General Information About the Bloomington Deficiency Kit [http://flys tocks.bio.indiana.edu/Browse/df-dp/dfkit-info.htm]

58. McConkey EH, Bielka H, Gordon J, Lastick SM, Lin A, Ogata K, Reboud JP, Traugh JA, Traut RR, Warner JR, et al.: Proposed uniform nomenclature for mammalian ribosomal proteins. Mol Gen Genet 1979, 169: I-6.

59. Wool IG, Chan YL, Gluck A, Suzuki K: The primary structure of rat ribosomal proteins $\mathrm{PO}, \mathrm{PI}$, and $\mathrm{P2}$ and a proposal for a uniform nomenclature for mammalian and yeast ribosomal proteins. Biochimie 1991, 73:861-870.

60. FlyBase: A Database of Drosophila Genes and Genomes [http://flybase.org/]

61. Cramton SE, Laski FA: string of pearls encodes Drosophila ribosomal protein S2, has Minute-like characteristics, and is required during oogenesis. Genetics 1994, 137:1039-1048.

62. Galloni M, Edgar BA: Cell-autonomous and non-autonomous growth-defective mutants of Drosophila melanogaster. Development 1999, 126:2365-2375.

63. Galloni M: Bonsai, a ribosomal protein SI 5 homolog, involved in gut mitochondrial activity and systemic growth. Dev Biol 2003, 264:482-494.

64. Cherry S, Doukas T, Armknecht S, Whelan S, Wang H, Sarnow P, 
Perrimon N: Genome-wide RNAi screen reveals a specific sensitivity of IRES-containing RNA viruses to host translation inhibition. Genes Dev 2005, 19:445-452.

65. Koyama Y, Katagiri S, Hanai S, Uchida K, Miwa M: Poly(ADPribose) polymerase interacts with novel Drosophila ribosomal proteins, L22 and L23a, with unique histone-like amino-terminal extensions. Gene 1999, 226:339-345.

66. Lee HS, Simon JA, Lis JT: Structure and expression of ubiquitin genes of Drosophila melanogaster. Mol Cell Biol 1988, 8:4727-4735.

67. Cabrera y, Poch HL, Arribas C, Izquierdo M: Sequence of a Drosophila cDNA encoding a ubiquitin gene fusion to a 52-aa ribosomal protein tail. Nucleic Acids Res 1990, I 8:3994.

68. Cabrera HL, Barrio R, Arribas C: Structure and expression of the Drosophila ubiquitin-52-amino-acid fusion-protein gene. Biochem J 1992, 286:281-288.

69. Barrio R, del Arco A, Cabrera HL, Arribas C: Structure and expression of the Drosophila ubiquitin-80-amino-acid fusionprotein gene. Biochem J 1994, 302:237-244.

70. Vaslet CA, O'Connell P, Izquierdo M, Rosbash M: Isolation and mapping of a cloned ribosomal protein gene of Drosophila melanogaster. Nature 1980, 285:674-676.

71. Burns DK, Stark BC, Macklin MD, Chooi WY: Isolation and characterization of cloned DNA sequences containing ribosomal protein genes of Drosophila melanogaster. Mol Cell Biol 1984, 4:2643-2652.

72. Qian S, Zhang JY, Kay MA, Jacobs-Lorena M: Structural analysis of the Drosophila rpAl gene, a member of the eucaryotic ' $A$ ' type ribosomal protein family. Nucleic Acids Res 1987, 15:987-1003.

73. Kay MA, Zhang JY, Jacobs-Lorena M: Identification and germline transformation of the ribosomal protein rp2I gene of Drosophila: complementation analysis with the Minute QIII locus reveals nonidentity. Mol Gen Genet 1988, 21 3:354-358.

74. Uechi T, Maeda N, Tanaka T, Kenmochi N: Functional second genes generated by retrotransposition of the $X$-linked ribosomal protein genes. Nucleic Acids Res 2002, 30:5369-5375.

75. Zhang Z, Harrison P, Gerstein M: Identification and analysis of over 2000 ribosomal protein pseudogenes in the human genome. Genome Res 2002, I 2: | 466-I482.

76. Brown SJ, Rhoads DD, Stewart MJ, Van Slyke B, Chen IT, Johnson TK, Denell RE, Roufa DJ: Ribosomal protein SI4 is encoded by a pair of highly conserved, adjacent genes on the $X$ chromosome of Drosophila melanogaster. Mol Cell Biol 1988, 8:4314-432।

77. Harrison PM, Milburn D, Zhang Z, Bertone P, Gerstein M: Identification of pseudogenes in the Drosophila melanogaster genome. Nucleic Acids Res 2003, 3 I: 1033-1037.

78. Parisi M, Nuttall R, Naiman D, Bouffard G, Malley J, Andrews J, Eastman S, Oliver B: Paucity of genes on the Drosophila $\mathbf{X}$ chromosome showing male-biased expression. Science 2003, 299:697-700.

79. Betran $E$, Thornton $K$, Long M: Retroposed new genes out of the $\boldsymbol{X}$ in Drosophila. Genome Res 2002, I2: 1854-1859.

80. Lifschytz $E$, Lindsley $D L$ : The role of $X$-chromosome inactivation during spermatogenesis. Proc Natl Acad Sci USA 1972, 69: I82-186.

81. Shigenobu S, Kitadate Y, Noda C, Kobayashi S: Molecular characterization of embryonic gonads by gene expression profiling in Drosophila melanogaster. Proc Natl Acad Sci USA 2006, 103:13728-13733.

82. Kai $T$, Williams $D$, Spradling AC: The expression profile of purified Drosophila germline stem cells. Dev Biol 2005, 283:486-502.

83. Saveanu C, Bienvenu D, Namane A, Gleizes PE, Gas N, Jacquier A, Fromont-Racine M: Nog2p, a putative GTPase associated with pre-60S subunits and required for late $60 \mathrm{~S}$ maturation steps. EMBO J 200 I, 20:6475-6484.

84. Zhao W, Bidwai AP, Glover CV: Interaction of casein kinase II with ribosomal protein L22 of Drosophila melanogaster. Biochem Biophys Res Commun 2002, 298:60-66.

85. Shigenobu S, Arita K, Kitadate Y, Noda C, Kobayashi S: Isolation of germline cells from Drosophila embryos by flow cytometry. Dev Growth Differentiation 2006, 48:49-57.

86. Stewart MJ, Denell R: The Drosophila ribosomal protein $S 6$ gene includes a 3' triplication that arose by unequal crossing-over. Mol Biol Evol 1993, 10: 1041-1047.

87. FlyBase: GBrowse - D. melanogaster [http://flybase.org/cgi-bin/ gbrowse/dmel/]
88. Elgin SC, Grewal SI: Heterochromatin: silence is golden. Curr Biol 2003, 13:R895-898.

89. Warner JR: The economics of ribosome biosynthesis in yeast. Trends Biochem Sci 1999, 24:437-440.

90. Ryder E, Blows F, Ashburner M, Bautista-Llacer R, Coulson D, Drummond J, Webster J, Gubb D, Gunton N, Johnson G, et al.: The DrosDel collection: a set of P-element insertions for generating custom chromosomal aberrations in Drosophila melanogaster. Genetics 2004, 167:797-8|3.

91. Ryder E, Ashburner M, Bautista-Llacer R, Drummond J, Webster J, Johnson G, Morley T, Chan YS, Blows F, Coulson D, et al:: The DrosDel Deletion Collection: A Drosophila Genomewide Chromosomal Deficiency Resource. Genetics 2007, 177:6I5-629.

92. Parks AL, Cook KR, Belvin M, Dompe NA, Fawcett R, Huppert K, Tan LR, Winter CG, Bogart KP, Deal JE, et al.: Systematic generation of high-resolution deletion coverage of the Drosophila melanogaster genome. Nat Genet 2004, 36:288-292.

93. Bellen HJ, Levis RW, Liao G, He Y, Carlson JW, Tsang G, Evans-Holm M, Hiesinger PR, Schulze KL, Rubin GM, et al.: The BDGP gene disruption project: single transposon insertions associated with 40\% of Drosophila genes. Genetics 2004, 167:76I-78I.

94. Thibault ST, Singer MA, Miyazaki WY, Milash B, Dompe NA, Singh CM, Buchholz R, Demsky M, Fawcett R, Francis-Lang HL, et al.: A complementary transposon tool kit for Drosophila melanogaster using $P$ and piggyBac. Nat Genet 2004, 36:283-287.

95. Dorer DR, Anane-Firempong A, Christensen AC: Ribosomal protein $\mathrm{SI} 4$ is not responsible for the Minute phenotype associated with the $M(I) 7 C$ locus in Drosophila melanogaster. Mol Gen Genet I99I, 230:8-II.

96. Qu S, Perlaky SE, Organ EL, Crawford D, Cavener DR: Mutations at the Ser50 residue of translation factor elF-2alpha dominantly affect developmental rate, body weight, and viability of Drosophila melanogaster. Gene Expression 1997, 6:349-360.

97. Kimball SR: Eukaryotic initiation factor elF2. Int J Biochem Cell Biol 1999, 3 I:25-29.

98. Krauss V, Reuter G: Two genes become one: the genes encoding heterochromatin protein $\mathrm{Su}(\mathrm{var}) 3-9$ and translation initiation factor subunit elF-2gamma are joined to a dicistronic unit in holometabolic insects. Genetics 2000, I 56: I I57- I I67.

99. Schotta G, Ebert A, Krauss V, Fischer A, Hoffmann J, Rea S, Jenuwein $T$, Dorn R, Reuter G: Central role of Drosophila SU(VAR)3-9 in histone H3-K9 methylation and heterochromatic gene silencing. EMBO J 2002, 21: I| $121-1|3|$.

100. Persson K: A Minute mutant with suppressor effect on the eye-colour gene zeste in Drosophila melanogaster. Hereditas 1976, 82:57-62.

I0I. Larsson J, Zhang J, Rasmuson-Lestander A: Mutations in the Drosophila melanogaster gene encoding S-adenosylmethionine synthetase suppress position-effect variegation. Genetics 1996, | 43:887-896.

102. Larsson J, Rasmuson-Lestander A: Somatic and germline clone analysis in mutants of the $\mathbf{S}$-adenosylmethionine synthetase encoding gene in Drosophila melanogaster. FEBS Lett 1998, 427:119-123

103. Gonzalez C, Molina I, Casal J, Ripoll P: Gross genetic dissection and interaction of the chromosomal region $95 \mathrm{E} ; 96 \mathrm{~F}$ of Drosophila melanogaster. Genetics 1989, I 23:371-377.

104. Frolov MV, Birchler JA: Mutation in PO, a dual function ribosomal protein/apurinic/apyrimidinic endonuclease, modifies gene expression and position effect variegation in Drosophila. Genetics 1998, I50: I487-I495.

105. Saeboe-Larssen S, Lyamouri M, Merriam J, Oksvold MP, Lambertsson A: Ribosomal protein insufficiency and the Minute syndrome in Drosophila: a dose-response relationship. Genetics 1998, 148:1215-1224

106. Patel R, Jacobs-Lorena M: Generation of Minute phenotypes by a transformed antisense ribosomal protein gene. Dev Genet 1992, 13:256-263.

107. Enerly E, Larsson J, Lambertsson A: Silencing the Drosophila ribosomal protein L/4 gene using targeted RNA interference causes distinct somatic anomalies. Gene 2003, 320:41-48.

108. Veitia RA: Exploring the etiology of haploinsufficiency. Bioessays 2002, 24:175-184.

109. Papp B, Pal C, Hurst LD: Dosage sensitivity and the evolution of gene families in yeast. Nature 2003, 424:194-197.

110. Baronas-Lowell DM, Warner JR: Ribosomal protein L30 is dispensable in the yeast Saccharomyces cerevisiae. Mol Cell Biol 
1990, 10:5235-5243.

III. Zhao Y, Sohn JH, Warner JR: Autoregulation in the biosynthesis of ribosomes. Mol Cell Biol 2003, 23:699-707.

I I2. Warner JR, Mitra G, Schwindinger WF, Studeny M, Fried HM: Saccharomyces cerevisiae coordinates accumulation of yeast ribosomal proteins by modulating mRNA splicing, translational initiation, and protein turnover. Mol Cell Biol 1985 , 5:|15|2-152|

I I3. Tamate HB, Patel RC, Riedl AE, Jacobs-Lorena M: Overproduction and translational regulation of rp49 ribosomal protein mRNA in transgenic Drosophila carrying extra copies of the gene. Mol Gen Genet 1990, 221:171-175.

I 14. Velculescu VE, Zhang L, Zhou W, Vogelstein J, Basrai MA, Bassett DE Jr, Hieter P, Vogelstein B, Kinzler KW: Characterization of the yeast transcriptome. Cell I997, 88:243-25I.

I 15. Tsay YF, Thompson JR, Rotenberg MO, Larkin JC, Woolford JL Jr: Ribosomal protein synthesis is not regulated at the translational level in Saccharomyces cerevisiae: balanced accumulation of ribosomal proteins LI6 and rp59 is mediated by turnover of excess protein. Genes Dev 1988, 2:664-676.

I16. Deutschbauer AM, Jaramillo DF, Proctor M, Kumm J, Hillenmeyer ME, Davis RW, Nislow C, Giaever G: Mechanisms of haploinsufficiency revealed by genome-wide profiling in yeast. Genetics 2005, I69:1915-1925

117. Schultz J: The Minute reaction in the development of Drosophila melanogaster. Genetics 1929, 14:366-4I9.

I 18. Lyamouri M, Enerly E, Kress H, Lambertsson A: Conservation of gene order, structure and sequence between three closely linked genes in Drosophila melanogaster and Drosophila virilis. Gene 2002, 282:199-206.

I 19. Yuan G, Klambt C, Bachellerie JP, Brosius J, Huttenhofer A: RNomics in Drosophila melanogaster: identification of 66 candidates for novel non-messenger RNAs. Nucleic Acids Res 2003, 3 I:2495-2507.

120. Accardo MC, Giordano E, Riccardo S, Digilio FA, lazzetti G, Calogero RA, Furia M: A computational search for box CID snoRNA genes in the Drosophila melanogaster genome. Bioinformatics 2004, 20:3293-330।.

121. Huang ZP, Zhou H, Liang D, Qu LH: Different expression strategy: multiple intronic gene clusters of box H/ACA snoRNA in Drosophila melanogaster. J Mol Biol 2004, 34I:669-683.

122. Huang ZP, Zhou H, He HL, Chen CL, Liang D, Qu LH: Genomewide analyses of two families of snoRNA genes from Drosophila melanogaster, demonstrating the extensive utilization of introns for coding of snoRNAs. Rna 2005, I I: | 303- | 3 | 6

123. Kiss T: Small nucleolar RNAs: an abundant group of noncoding RNAs with diverse cellular functions. Cell 2002 , 109: $145-148$.

124. Tycowski KT, Steitz JA: Non-coding snoRNA host genes in Drosophila: expression strategies for modification guide snoRNAs. Eur J Cell Biol 2001, 80: I |9-|25.

125. Rudra D, Warner JR: What better measure than ribosome synthesis? Genes Dev 2004, I 8:243I-2436.

126. Weijers D, Franke-van Dijk M, Vencken RJ, Quint A, Hooykaas P Offringa R: An Arabidopsis Minute-like phenotype caused by a semi-dominant mutation in a RIBOSOMAL PROTEIN S5 gene. Development 200I, I 28:4289-4299.

127. Amsterdam A, Sadler KC, Lai K, Farrington S, Bronson RT, Lees JA Hopkins N: Many ribosomal protein genes are cancer genes in zebrafish. PLoS Biol 2004, 2:El 39.

128. Gazda HT, Zhong R, Long L, Niewiadomska E, Lipton JM, Ploszynska A, Zaucha JM, Vlachos A, Atsidaftos E, Viskochil DH, et al:: RNA and protein evidence for haplo-insufficiency in Diamond-Blackfan anaemia patients with RPSI9 mutations. $\mathrm{Br} J$ Haemato 2004, I 27: 105-I I3.

129. Oliver ER, Saunders TL, Tarle SA, Glaser T: Ribosomal protein L24 defect in belly spot and tail (Bst), a mouse Minute. Development 2004, I 3 I:3907-3920.

130. Leger-Silvestre I, Caffrey JM, Dawaliby R, Alvarez-Arias DA, Gas N, Bertolone SJ, Gleizes PE, Ellis SR: Specific role for yeast homologs of the Diamond Blackfan anemia-associated Rps I 9 protein in ribosome synthesis. J Biol Chem 2005, 280:38I77-38I85.

13I. Panic L, Tamarut S, Sticker-Jantscheff M, Barkic M, Solter D, Uzelac M, Grabusic K, Volarevic S: Ribosomal protein S6 gene haploinsufficiency is associated with activation of a p53-dependent checkpoint during gastrulation. Mol Cell Biol 2006, 26:8880-8891.
132. Panic L, Montagne J, Cokaric M, Volarevic S: S6-haploinsufficiency activates the p53 tumor suppressor. Cell Cycle 2007, 6:20-24.

133. Huang SL, Baker BS: The mutability of the Minute loci of Drosophila melanogaster with ethyl methanesulfonate. Mutat Res 1976, 34:407-4|4.

134. Spencer FA, Hoffmann FM, Gelbart WM: Decapentaplegic: a gene complex affecting morphogenesis in Drosophila melanogaster. Cell 1982, 28:45I-46I.

135. Karch F, Weiffenbach B, Peifer M, Bender W, Duncan I, Celniker S, Crosby $M$, Lewis EB: The abdominal region of the bithorax complex. Cell 1985, 43:8I-96

136. Dorer DR, Rudnick JA, Moriyama EN, Christensen AC: A family of genes clustered at the Triplo-lethal locus of Drosophila melanogaster has an unusual evolutionary history and significant synteny with Anopheles gambiae. Genetics 2003, I 65:6 I3-62I.

137. Prado A, Canal I, Ferrus A: The haplolethal region at the I6F gene cluster of Drosophila melanogaster: structure and function. Genetics 1999, I5 I:163-175.

138. Lefevre G Jr: The eccentricity of vermilion deficiencies in Drosophila melanogaster. Genetics 1969, 63:589-600.

139. National Center for Biotechnology Information: Entrez Protein [http://www.ncbi.nlm.nih.gov/sites/entrez?db=Protein]

140. FlyBase: BLAST [http://flybase.org/blast/]

14I. ExPASy Proteomics Server: Compute pl/Mw tool [http:// www.expasy.org/tools/pi_tool.html]

142. Pôle Bioinformatique Lyonnais, Network Protein Sequence Analysis: CLUSTALW [http://npsa-pbil.ibcp.fr/cgi-bin/ npsa_automat.pl?page=npsa_clustalw.html]

143. Combet C, Blanchet C, Geourjon C, Deleage G: NPS@: network protein sequence analysis. Trends Biochem Sci 2000, 25: I47-I 50.

144. Yang Z: PAML: a program package for phylogenetic analysis by maximum likelihood. Comput Appl Biosci 1997, I 3:555-556.

145. Kent WJ: BLAT - the BLAST-like alignment tool. Genome Res 2002, 12:656-664.

146. UCSC Genome Bioinformatics [http://genome.ucsc.edu/]

147. EBI Sequence Analysis Tools: ClustalW [http://www.ebi.ac.uk/ Tools/clustalw/index.html]

148. National Center for Biotechnology Information: HomoloGene [http://www.ncbi.nlm.nih.gov/sites/ent rez?db=homologene]

149. Powell JR: Progress and Prospects in Evolutionary Biology: The Drosophila Model New York: Oxford University Press; 1997.

150. FlyBase: Map Conversion Table [http://flybase.org/static_pages/ docs/cytotable3.html]

15I. Hoskins RA, Smith CD, Carlson JW, Carvalho AB, Halpern A Kaminker JS, Kennedy C, Mungall CJ, Sullivan BA, Sutton GG, et al.: Heterochromatic sequences in a Drosophila whole-genome shotgun assembly. Genome Biol 2002, 3:RESEARCH0085.

I52. FlyBase: BAC In Situ Images [http://cane.bio.indiana.edu:7062/ images/lk/bac_insitu_pic/]

153. Schalet AP: The distribution of and complementation relationships between spontaneous $X$-linked recessive lethal mutations recovered from crossing long-term laboratory stocks of Drosophila melanogaster. Mutat Res 1986, I 63: I I 5- I 44.

154. Golic KG, Golic MM: Engineering the Drosophila genome: chromosome rearrangements by design. Genetics 1996, |44:|693-|7||

155. Qian S, Hongo S, Jacobs-Lorena M: Antisense ribosomal protein gene expression specifically disrupts oogenesis in Drosophila melanogaster. Proc Natl Acad Sci USA 1988, 85:9601-9605.

156. Reed B: The genetic analysis of endoreduplication in Drosophila melanogaster. In PhD thesis University of Cambridge; 1992.

157. Kongsuwan K, Dellavalle RP, Merriam J: Deficiency analysis of the tip of chromosome $3 \mathbf{R}$ in Drosophila melanogaster. Genetics 1986, I | 2:539-550. 